NBER WORKING PAPER SERIES

\title{
PATIENT COST-SHARING, HOSPITALIZATION OFFSETS, AND THE DESIGN OF OPTIMAL HEALTH INSURANCE FOR THE ELDERLY
}

\author{
Amitabh Chandra \\ Jonathan Gruber \\ Robin McKnight \\ Working Paper 12972 \\ http://www.nber.org/papers/w12972 \\ NATIONAL BUREAU OF ECONOMIC RESEARCH \\ 1050 Massachusetts Avenue \\ Cambridge, MA 02138 \\ March 2007
}

We thank, without implicating, Kathy Donneson and Terrence Newsome from CalPERS for invaluable technical assistance, Dan Gottlieb and Weiping Zhou at Dartmouth Medical School for assistance with the Medicare data, Drs. Dhruv Bansal, Phoutie Bansal, Julie Bynum, Amy Richardson, and Ivy Tiu for assisting with the classification of prescription drugs, James deBenedetti, Michele Douglas, Will Manning, Doug Miller, April Omoto, Doug Staiger, and seminar participants at the Annual Health Economics Conference, the NBER, UC-Davis, and the Pharmaceutical Economics and Policy Council for helpful comments. Gruber acknowledges support from the Kaiser Family Foundation and the National Institute on Aging, and Chandra from NIA P01 AG19783-02, an NBER Aging Fellowship, and the Nelson Rockefeller Center at Dartmouth. The views expressed herein are those of the author(s) and do not necessarily reflect the views of the National Bureau of Economic Research.

(C) 2007 by Amitabh Chandra, Jonathan Gruber, and Robin McKnight. All rights reserved. Short sections of text, not to exceed two paragraphs, may be quoted without explicit permission provided that full credit, including $\odot$ notice, is given to the source. 
Patient Cost-Sharing, Hospitalization Offsets, and the Design of Optimal Health Insurance

for the Elderly

Amitabh Chandra, Jonathan Gruber, and Robin McKnight

NBER Working Paper No. 12972

March 2007, Revised June 2009

JEL No. I1

\begin{abstract}
Patient cost-sharing for primary care and prescription drugs is designed to reduce the prevalence of moral hazard in medical utilization. Yet the success of this strategy depends on two factors: the elasticity of demand for those medical goods, and the risk of downstream hospitalizations by reducing access to beneficial health care. Surprisingly, we know little about either of these factors for the elderly, the most intensive consumers of health care in our country. We remedy both of these deficiencies by studying a policy change that raised patient cost-sharing for retired public employees in California. We find that physician office visits and prescription drug utilization are price sensitive, with implied arc-elasticities that are similar to those of the famous RAND Health Insurance Experiment (HIE). However, unlike the HIE, we find substantial "offset" effects in terms of increased hospital utilization in response to the combination of higher copayments for physicians and prescription drugs. These offset effects are concentrated in patients for whom medical care is presumably efficacious: those with a chronic disease. Finally, we find that the savings from increased cost-sharing accrue mostly to the supplemental insurer, while the costs of increased hospitalization accrue mostly to Medicare; thus, there is a fiscal externality associated with cost-sharing increases by supplemental insurers. Our findings suggest that health insurance should be tied to underlying health status, with chronically ill patients facing lower cost-sharing. We also conclude that the externalities to Medicare from supplemental insurance coverage may be more modest than previously suggested due to these offsets.
\end{abstract}

Amitabh Chandra

John F. Kennedy School of Government

Harvard University

79 JFK Street

Cambridge, MA 02138

and NBER

amitabh_chandra@ksg.harvard.edu

Jonathan Gruber

MIT Department of Economics

E52-355

50 Memorial Drive

Cambridge, MA 02142-1347

and NBER

gruberj@mit.edu

\author{
Robin McKnight \\ Department of Economics \\ Wellesley College \\ 106 Central Street \\ Wellesley, MA 02481 \\ and NBER \\ rmcknigh@wellesley.edu
}


The elderly are the most intensive consumers of health care in the United States today. Individuals over age 65 consume $36 \%$ of health care in the U.S., despite representing only $13 \%$ of the population (CMS, 2005). The Medicare program that insures the nation's elderly (as well as the disabled) is the third largest expenditure item for the Federal government, and is projected to exceed Social Security by 2024 (Board of Trustees, 2005). This rapid growth in program expenditures was reinforced by the recent introduction of Medicare Part D, a new plan providing coverage for the outpatient prescription drugs used by Medicare beneficiaries.

The Federal government has undertaken a variety of strategies to control Medicare program growth on the supply side, from the introduction of prospective reimbursement for hospitals to reductions in provider reimbursement rates. Yet Medicare spending growth has continued unabated. Recently, therefore, there has been a growing interest in demand-side approaches to controlling system costs, through higher patient costs which would induce more price sensitivity in medical spending.

Using demand-side approaches to constrain the growth of Medicare spending is hampered by three difficulties. First, surprisingly, we have no evidence on the price sensitivity of the elderly to point-of-service medical costs. For the non-elderly, the question of the sensitivity of medical consumption to its price was addressed by the famous RAND Health Insurance Experiment, one of the most important pieces of social policy research of the post-war period. The RAND HIE randomized individuals across health insurance plans of differing generosity with respect to patient costs, and the results showed that higher patient payments significantly reduced medical care utilization, without any adverse health outcomes on average (Manning et al. (1987), Newhouse (1993)). While this evidence is now almost thirty years old, it has remained the "gold standard" for 
evaluating the impact of patient-side cost-sharing and the design of insurance benefits.

However, the HIE estimates the elasticity of demand in a fee-for-service environment that may exhibit very different responsiveness to prices than the world of managed care. Moreover, changes in the practice of medicine, including the increased use of prescription drugs, the growth of imaging and diagnostic technology and the development of minimally invasive surgery, may imply a structural change in the elasticity of medical demand and the health impacts of any utilization reductions. Finally, even absent other changes, it is unclear whether the results of the HIE apply to the elderly population that was not included in this social experiment.

Second, there may be particular concern that increased cost-sharing for the elderly can cause offsetting rises in medical costs elsewhere in the system. The HIE did test this "offset effect" for the non-elderly, and found no evidence, for example, that higher outpatient cost-sharing led to more use of inpatient services. Recent research on prescription drug utilization by the non-elderly, however, has shown that higher copayments lead to lower utilization of maintenance drugs for chronic illness, which implies (although it has yet to be proved) that an offset effect may exist (Goldman et al., 2006). Once again, this is a major concern for the elderly who are the most intensive users of expensive medical services.

A final complication is the fact that Medicare already has quite substantial cost-sharing requirements, with an uncapped $20 \%$ coinsurance rate for physician services and a high deductible for hospital utilization. As a result, most enrollees have some form of supplemental coverage for their medical spending, either provided by an employer, purchased on their own, or provided through state Medicaid programs. Thus, introducing demand-side price sensitivity requires involving these supplemental insurers who control the first-dollar exposure of the elderly to medical 
costs. This can be difficult because the interests of the first-dollar insurer and the last-dollar insurer may not be readily aligned. In particular, there are long-standing concerns about the fiscal externality on Medicare from supplemental coverage; by providing first-dollar coverage, these policies increase utilization, raising the costs to Medicare. In this paper, we provide new evidence on all three of these issues by studying a major set of copayment changes in a modern, managed care environment. Facing mounting fiscal pressure from health plan cost increases, the California Public Employees Retirement System (CalPERS) Board, the third largest purchaser of health insurance in the United States, enacted a series of substantial copayment increases in February 2001. For the remainder of 2001, copayments were increased for the Preferred Provider Organizations (PPOs) that were offered by the state to its employees. Then, beginning in 2002, copayments were increased for the remaining enrollees in Health Maintenance Organizations (HMOs) operating under contract to CalPERS. Importantly, these changes occurred not just for active employees, but for retirees receiving supplemental insurance through the plans as well. The result was a staggered set of copayment changes that allow us to carefully evaluate their impact on the medical care utilization of the elderly. ${ }^{1}$

To evaluate these policy changes, we have compiled (with the assistance of CalPERS) a comprehensive database of all medical utilization data ${ }^{2}$ for those enrolled continuously in several of the CalPERS plans from January, 2000 through September, 2003. This database has information on every medical contact, allowing us to comprehensively study the effect of these copayment policy changes on a wide variety of medical utilization outcomes.

We have a number of interesting findings. First, we find that both physician office visits

\footnotetext{
${ }^{1}$ We can, of course, also study utilization of the non-elderly, but this is of less interest because of existing studies. We intend to investigate responses among the non-elderly in future work.
} 
and prescription drug utilization are modestly price sensitive among the elderly, with implied arcelasticities that are similar to those found in the HIE for the non-elderly. Second, unlike the HIE, we find significant "offset" effects in terms of increased hospital utilization in response to the combination of higher copayments for physicians and prescription drugs. These offset effects are concentrated, however, in the most ill populations, particularly those who had a chronic illness or who had high previous medical spending. Finally, we find that the savings from increased costsharing accrue mostly to the supplemental insurer, CalPERS, while the costs of increased hospitalization accrue mostly to Medicare. As a result, when supplemental insurance cost-sharing rises, the net fiscal benefits for Medicare are much smaller than previously recognized.

Our paper proceeds as follows. Part I provides some background on previous work in this area and on the policy change we are studying. Part II describes the data and empirical strategy. Part III presents our basic set of results on price sensitivity. Part IV then extends the results in a variety of directions. Part V concludes.

\section{Part I: Background}

\section{Previous Work on Price Sensitivity of Medical Demand}

The previous literature on the impact of copayment changes can be broken down into three "eras". The first is the work on elasticities of demand that pre-dated the RAND HIE. Most of this work simply regressed medical care spending on the level of coinsurance, either at the family or the state level (e.g. Feldstein, 1971; Rosett and Huang, 1973). This work faced the fundamental problem that the level of coinsurance is a function both of choice of insurance plan and of previous

\footnotetext{
${ }^{2}$ All claims information used was de-identified prior to receipt for both CalPERS and study researchers.
} 
medical spending (since the level of coinsurance varies by whether individuals are below or above the deductible level, for example), and both of these are quite likely to be correlated with contemporaneous medical spending. One of the earliest studies to use quasi-experimental variation was Phelps and Newhouse (1972). This study examined the impact of a change in cost-sharing in the Stanford medical plan, but had no control group to capture general time trends in demand that might confound their analysis.

The second era is the RAND HIE, which is summarized in Manning et al. (1987) and Newhouse (1993). In the wake of the unconvincing evidence from the first era of the literature, the government, in the mid-1970s, funded a massive social experiment to evaluate the impact of costsharing on demand. Families who enrolled in the HIE were randomly assigned to plans with widely varying coinsurance and deductible amounts. This random assignment guaranteed that the results could be used to cleanly infer the impacts of varying coinsurance rates on demand. The HIE showed that medical services were modestly price responsive, with an overall estimated arcelasticity of medical spending in the range of -0.2 .

There were a variety of other important findings that are summarized in Newhouse (1993), but three stand out for our purposes. First, the reduction in medical utilization was relatively uniform: for almost every category of care, utilization fell for both (in theory) "effective" and "ineffective" care. Second, despite the reduced medical care that resulted from high patient coinsurance, those in high coinsurance plans were in no worse health, on average. Even among subgroups such as the poor or the unhealthy, there was no systematic relationship between patient coinsurance and health. There is one exception that has received much attention: the study found sizeable advantages of free care for the share of the sample that was both low income (bottom $20 \%$ 
of the income distribution) and chronically ill (least healthy $25 \%$ of the sample). In particular, such individuals saw large declines in their blood pressure on the free care plan relative to the coinsurance plans; improvements in respiratory functioning; and improvements in vision and dental health. ${ }^{3}$ Finally, the study found no "offset effects": there was no evidence that high coinsurance, by causing individuals to forgo efficacious preventive care, would raise costs through inappropriate care later on (particularly at the hospital). On the experimental plan with higher outpatient coinsurance, but no inpatient charges, hospital utilization actually fell rather than rose.

The third era includes studies subsequent to the HIE: Cherkin, Grothaus and Wagner (1989) studied the introduction of a $\$ 5$ copayment rate for state employees enrolled in an HMO in Washington state, in the mid-1980s, relative to federal employees. They find a sizeable reduction in office visits. Selby, Fireman and Swain (1996), examined the introduction of an emergency room copayment for some firms insured by the Kaiser Permanente HMO plan in the early 1990s, relative to a control group of those firms who did not see this copayment increase. They find a significant decline in emergency room utilization, with no evidence of adverse impacts on health. Eichner (1996) studied the impact on utilization in a fee-for-service plan, using the fact that adults in a family face different prices as injuries to their children push them above out-of-pocket cost sharing limits, and he finds an elasticity of spending of -0.3 to -0.4 .

There is also a recent and sizeable literature that focuses on the price elasticity of demand for prescription drugs. Studies such as those by Goldman et al. (2004), Landsman et al. (2005) and Gaynor, Li and Vogt (2007) find that prescription drug use is price sensitive, with low elasticities of

\footnotetext{
${ }^{3}$ While this potential caveat has garnered much attention, however, it is important to recognize its limitations. First, none of the estimated effects on the health of this group are statistically significant in a traditional sense; the samples are simply too small to have much confidence in these results. Second, as Newhouse (1993) emphasizes, there is no evidence of overall health benefits for
} 
around -0.1 for drugs used to maintain chronic conditions (such as ACE inhibitors or statins), but much higher elasticities of around -0.3 to -0.4 for drugs used for acute conditions (such as Cox-2 inhibitors for pain management).

These studies have two important limitations. First, they are exclusively focused on the non-elderly, ignoring the elderly patients who are responsible for a massive, and growing, share of public health spending. There are studies that focus on elders, as reviewed by Rice and Matsuoka (2004), but virtually all of these studies are either cross-sectional comparisons of elders with and without generous drug coverage, or simple before/after comparisons of drug copayment changes (which suffer from the problem of uncontrolled trends in drug utilization). The one exception is Johnson et. al. (1997), who studied an increase in copayments in one Medicare HMO, using a different Medicare HMO as a control. This study finds no consistent impact of changes in copayments on drug utilization. The second major limitation of this previous literature is that it does not go on, as RAND did, to examine the implications of changing utilization for either health or utilization elsewhere in the medical system. ${ }^{4}$ One notable exception is Gaynor, Li and Vogt (2007) which found evidence of a spending offset in the non-elderly population.

A new paper by Finkelstein (2007) paints a more dramatic picture by looking at the introduction of the Medicare program. Using variation in pre-existing levels of insurance coverage before the program was introduced, Finkelstein finds an enormous response of spending to the provision of insurance coverage, with an implied elasticity that is six times larger than in the HIE.

this group, just evidence along these three measures; for other measures, such as varicose veins, health is worse in the free care group.

${ }^{4}$ Recent work by Goldman et al. (2006) argues that higher copayments for prescription drugs leads to more hospitalizations, but this claim is based on combining the fact that higher copayments lead to less drug utilization with an estimate of the relationship between drug utilization and hospitalization. The latter parameter is obtained by comparing hospitalization rates among those who do and do not comply with their drug regimes. This may not reflect the reduction in drug use due to copayments so much as the type of 
This suggests either that the elderly are more price-sensitive than the non-elderly, or that a systemwide change of this nature had a bigger effect than individual randomization.

\section{Previous Work on the Supplemental Insurance}

Of particular relevance to our analysis is the long-standing policy concern about the design of supplemental insurance for Medicare. In particular, because supplemental insurance insulates beneficiaries from Medicare's cost-sharing, it likely increases their utilization of Medicare-covered services (so long as those services are not inelastically demanded). Atherly (2001) provides a review of the research history, observing that the literature consistently finds a positive correlation between supplemental insurance and Medicare expenditures. Estimates of the effect of this externality on Medicare range from zero (Wolfe and Goddeeris, 1991) to $72 \%$ increases in Medicare charges among unhealthy individuals (McCall et al., 1991). However, none of the existing papers is able to fully surmount the important selection problem in the holding of Medigap policies documented by Ettner (1997). Studies such as Lillard and Rogowski (1995) use past work history as an instrument for employer-provided Medigap coverage, but past work history is itself likely correlated with demand for medical care and health. Moreover, none of these studies assesses the impact of varying copayments for the elderly, only aggregate impact of having or not having supplemental insurance.

Goldman and Philipson (2007) raise the important, related point that optimal health insurance design should not merely consider own-price elasticities of demand for medical care, but also cross-price elasticities. In the context of supplemental insurance, it is plausible that the costsharing structure chosen by the supplemental insurer affects both the "insured good" (such as office 
visits) and "other services" (such as hospitalizations) that impose differential costs on Medicare. Thus, the net external effect of supplemental insurance on Medicare costs may be composed of two parts: the increase in utilization of the affected service, due to a decrease in the beneficiary's out-ofpocket costs, and an offsetting decrease in utilization of a substitute service (or an increase in utilization of a complementary service).

\section{The Institutional Setting}

Our analysis focuses on changes in copayments for the health plans offered to public employees by the state of California through the CalPERS program. This program provides insurance to 1.2 million of California's active and retired civil servants and their dependents, making it the third largest purchaser of health insurance in the nation (behind the Federal Government and General Motors) (CalPERS, 2006). Employees are offered a choice of two staterun Preferred Provider Organizations (PPOs), PersCARE and PersChoice, as well as a variety of state-sanctioned HMO choices that have changed over time. Choices are made every year during the month-long open enrollment period, between mid-September and mid-October. For retirees, our population of interest, the state provides supplemental insurance that "wraps around" the coverage provided by the Medicare program.

The empirical approach of this project revolves around the policy change put in place by CalPERS. The genesis of this policy change was the rapidly rising health care costs in the selffunded CalPERS plans. There was a 47\% increase in PPO enrollment from 1997 through 2000, with another $25 \%$ increase expected for 2001 , due partly to movements out of the HMO plans and lack of HMO availability in some areas. There were also significant rises in costs per member, due 
to both increased provider prices (reflecting the nationwide trend towards tougher bargaining by providers with managed care organizations) and increased utilization, particularly of prescription drugs. As a result, the plan reserves had fallen from a level equal to 6.3 months of claims experience to basically zero (so that premium income was roughly equal to claims expenditures) (CalPERS, 2000).

In response to these pressures, the board of CalPERS in December 2000 voted to raise the copayments in their PPO plans as of February 2001. They then decided, in April 2001, to follow suit for the HMO plans that contract through CalPERS, beginning in January 2002. This policy change included a variety of copayment changes for the non-supplemental population. For the supplemental population, there were two changes:

1. A rise in physician office visit copayments for the HMOs from $\$ 0$ to $\$ 10$ in 2002 . There was no corresponding change for PPOs in 2001.

2. A rise in copayments for prescription drugs for all PPO plans from $\$ 5$ for generics and $\$ 10$ for name brands to $\$ 5$ for generics, $\$ 15$ for formulary name brands, and \$30 for nonformulary name brand prescriptions, as well as a rise in mail order prescription copayments from $\$ 5$ to $\$ 10 / \$ 25 / \$ 45$, with a $\$ 1000$ stop-loss in 2001 . HMOs had a similar rise in copayments for prescription drugs in 2002; for HMOs, however, copayments prior to the policy change were $\$ 1$ for almost all enrollees, and did not differ for generics and name brands. 5

\section{Part II: Data and Empirical Strategy}

\footnotetext{
${ }^{5}$ The copayment was $\$ 1$ for one of our HMOs and $\$ 5$ for the other, but the former HMO represents $98 \%$ of the continuously enrolled HMO sample.
} 
Data

For our analysis, we use a comprehensive database of all medical utilization data for four of the CalPERS plans between January, 2000 and September, 2003. We focus on a panel of Medicare supplemental plan members who were continuously enrolled in their plan during our sample period, noting that this sample is not necessarily representative of the Medicare population. The resulting data set includes information on medical utilization by 70,912 members; $93 \%$ of these members were over the age of 65 in January 2000.

By selecting a sample of continuously enrolled individuals, we risk potentially mismeasuring the population responsiveness of individuals to copayment changes. If individuals switch out of plans raising copayments, and the individuals who switch have a sensitivity of medical care utilization with respect to price that is higher (lower) than average, then our estimated elasticities in this sample will be biased downward (upward) in absolute value. Indeed, a special open enrollment period was established, between December 2000 and the end of January 2001, with the specific purpose of allowing plan members to switch plans in response the announcement of PPO copayment increases. Such switching, however, does not seem to be of sufficient importance to bias our results. We find, for example, that $92 \%$ of the members who were enrolled in our PPOs in February 2000 remained enrolled in the same plan in February 2001, despite the anticipated copayment increases in February 2001. Indeed, this $92 \%$ retention rate was slightly higher than the 91\% retention rate, over the same period, at HMOs that were not expecting a copayment increase. Similarly, $92 \%$ of the members who were enrolled in our HMOs in February 2001 remained enrolled in the same plan in February 2002. Again, despite the January 2002 copayment increase, the HMO retention rate was slightly higher than the $90 \%$ retention rate for the PPOs over the same 
period. ${ }^{6}$ As a result, when we re-estimate our models using the full sample of enrollees (including individuals who both enter and exit our plans), we get almost identical results to those presented here. $^{7}$

For each individual, we measure office visit utilization by the number of medical encounters which occurred in an office or outpatient setting during the month. We measure drug utilization by the number of prescriptions filled during the month. We measure hospital utilization with an indicator for whether or not the individual spent any days in the hospital during the month.

In our analysis, we compute an average of each utilization measure for each plan in each month, which yields 180 observations in our final data set ( 45 months*4 plans). Thus, each of the 180 observations on a utilization measure in our final data set reflects the average utilization per person among all continuously enrolled members of a single plan in a given month. In order to document the impact of the policy change on copayments, we also calculate average copayments and deductibles across all visits (or prescription drug purchases) for each plan in each month. Each of the 180 observations on copayments in our final data set reflects the average copayment per visit (or prescription drug purchase) in a single plan in a single month. ${ }^{8}$

We analyze the impact of these policy changes on medical spending as well as utilization. Ideally, we would do this by having the payments associated with every medical encounter, and we would redo our analysis using these payments as the dependent variable. In practice, however,

\footnotetext{
${ }^{6}$ Both plans experienced $92 \%$ retention rates over the one-year period between February 2002 and February 2003, when neither experienced a copayment change. This fact increases our confidence that the plans did not experience unusual attrition as a result of the policy changes.

${ }^{7}$ One exception to this statement is our results for hospitalizations. In the full sample, we get a small negative effect on overall hospitalizations for the 2002 change, rather than the small positive effect reported below. But this appears to reflect pre-existing trends in the full sample of data, and our key results on hospitalization for the chronically ill are very similar. All the full-sample results are available from the authors upon request.

${ }^{8}$ When we analyze the 2002 copayment increase for office visits, we exclude office visit data from 2000. One of the plans changed their coding of office visits between 2000 and 2001, generating a discontinuity in the data that is unrelated to any policy changes. To avoid any spurious results based on this reporting change, we simply exclude all office visit data prior to 2001.
} 
there is not any financial information on payments attached to HMO claims. We therefore pursue an alternative approach where we use available data on total payments from PPO claims to impute total payments to each claim based on the primary diagnosis category of the office visit (or the NDC code of the prescription drug), and the average payment for an office visit with that diagnosis category (or for that specific drug) among all PPO claims. Following Medicare Part B policy, we assume that Medicare made $80 \%$ of the total payments for office visits and that the CalPERS supplemental insurance plan paid the difference between the remaining $20 \%$ and any patient copayments. For drugs, we assume that the CalPERS supplemental insurance plan made all payments above the patient copayments.

For hospitalizations, where Medicare's share of total payments is not a fixed percentage, we followed a different methodology. Total hospital payments are the sum of imputed CalPERS insurance payments, imputed Medicare payments, and any actual cost-sharing paid by the patient. We imputed the first component based on the diagnosis code of the hospitalization and the average insurance payment for hospitalizations with the same diagnosis in the PPO data. We imputed Medicare's payments based on the diagnosis code of the hospitalization and the average Medicare payment for hospitalizations with that diagnosis code, using the universe of Medicare claims in the state of California during our sample period. ${ }^{9}$ For cost-sharing, we used the actual amounts that were reported in the data. We then constructed total hospital payments as the sum of these three

\footnotetext{
${ }^{9}$ We used a $100 \%$ sample of Medicare Part A payments for patients whose residence was in California at the time of the hospitalization; Medicare patients who reside in other states but were in California at the time of hospitalization were excluded. For this sample of patients, we constructed average Medicare payments by principal diagnosis code for hospitalizations that occurred between January 2000 and September 2003. In order to reduce sampling error associated with rare diagnoses, diagnosis codes were first aggregated to levels indicated by the Clinical Classification System (CCS). To capture payments made to physicians for inhospital services rendered during these hospital stays, we used a 20\% random sample of the above Part A sample for whom we had Part B claims. We further restricted these claims to those whose dates corresponded to a hospitalization (including the dates of admission and discharge) and whose service place was an overnight inpatient visit. We merged payments for these services with the corresponding Part A hospitalization. This analysis was performed at the Center for the Evaluative Clinical Sciences at Dartmouth Medical School, and the relevant SAS programs are available from the authors on request.
} 
payments.

A clear concern with our approach for physician and hospital visits is that we assign the average payments per diagnosis, whereas ideally we would like to use the marginal payments for the given admission. If we had complete data on all procedures performed at the hospital and at the office, we could do this, but our data include limited information on procedures. The bias from using average rather than marginal payments is unclear, but we have explored one exercise to assess its importance. Among those admitted to the hospital, we have regressed length of hospital stay on the policy dummy in our difference-in-difference framework. If the marginal patients admitted due to higher physician/drug copayments are very different than the average patient admitted, then we should see a marginal change in the length of stay for hospital patients. In fact, there is no significant effect on length of stay, providing at least crude evidence that the marginal and average patients are not very different.

\section{Empirical Strategy}

Our analysis of this quasi-experimental change in CalPERS policy is fairly straightforward. We begin by estimating difference-in-difference models of the form:

$$
\mathrm{UTIL}_{\mathrm{pt}}=\alpha+\beta \mathrm{HIPAY}_{\mathrm{pt}}+\delta_{\mathrm{p}}+\lambda_{\mathrm{t}}+\varepsilon_{\mathrm{pt}}
$$

Where UTIL is a measure of utilization (or out-of-pocket costs) for plan $p$ in month $t, \alpha$ is a constant term, HIPAY is a dummy for increased copayments in plan $p$ in month $t$ (specifically, an interaction of an indicator variable for being in a plan where greater cost-sharing is instituted and an indicator for being in the post-increase era), and $\delta_{p}$ and $\lambda_{t}$ are plan and month fixed effects, 
respectively. ${ }^{10}$ In this model, the effect of the copayment change is identified by $\beta$, which

measures the change in utilization in the plans with a copayment change relative to those without.

For each type of utilization, we estimate two models of this type: one which separately identifies

effects on PPOs (focusing on data from January 2000 to December 2001), and another which

separately identifies effects on HMOs (focusing on data from February 2001 to September 2003).

Regressions are weighted by the number of plan members who are continuously enrolled during our sample period in each plan.

There are two potential problems with this approach. First, utilization is likely autocorrelated within plans; this autocorrelation causes the standard errors in ordinary regressions to be understated. To address this issue, we estimate our regressions using Generalized Least Squares (GLS) allowing for plan-specific autocorrelation as well as plan-specific heteroskedasticity. ${ }^{11}$

Second, there may be underlying trends in utilization, which can confound the estimation of the causal effects that we are interested in. A particularly worrisome source of such trends for the HMO analysis is the earlier PPO policy change. That is, our difference-in-difference analysis for the HMO policy change compares the change in utilization in the HMOs between the pre-policy period (February 2001 - December 2001) and the post-policy period (January 2002 - September

\footnotetext{
${ }^{10}$ Because we use a fixed panel of enrollees, there are no time-varying differences between HMO and PPO enrollees. Any fixed differences are captured by the plan fixed effects in our regressions. We chose to perform our analysis at the plan-month level in order to be as conservative as possible about our standard errors.

${ }^{11}$ This is a non-trivial issue that we have explored from a variety of angles. The GLS procedure reports $\hat{\beta}=\left(X^{\prime} \hat{\Omega}^{-1} X\right)^{-1} X^{\prime} \hat{\Omega}^{-1} y$, and its variance as $\operatorname{var}(\hat{\beta})=\left(X^{\prime} \hat{\Omega}^{-1} X\right)^{-1}$. The relevant variance-covariance matrix is estimated as $\hat{\Omega}=\Sigma \otimes I_{T x T}$, and operationalized with $\hat{\Sigma}_{i, j}=\hat{e}_{i} \hat{e}_{j} / T$ (where $\mathrm{T}$ is the number of time-periods and $\Sigma$ is a square matrix of dimension equal to the number of plans). The most natural solution to our problem would be to follow the insights of Bertrand, Duflo and Mullainathan (2004) and cluster on the four plans. However, the approach relies critically on the asymptotic justification that the number of clusters goes to infinity; with too few clusters the cluster-robust standard errors are biased downwards severely. Empirically, we found that this approach produced standard-errors that were $0 \%-35 \%$ smaller than those obtained from our GLS procedure. Alternatively, if we ignore the potential
} 
2003) to the change in utilization in the PPOs over the same periods. If the policy change in the

PPOs had immediate effects in February, 2001, this is not a problem. But it is possible that utilization in the PPOs adjusted slowly to the PPO policy change, with full adjustment only by the end of 2001. If this were the case, absent any other change, there would be a negative utilization difference between 2001 and 2002 for the PPO, leading to a spurious positive difference-indifference estimate of the effect of the 2002 policy change on HMO utilization. To deal with this concern, we present dynamic models of the policy change effect, estimating separate treatment effects for each quarter before and after the policy change. ${ }^{12}$ In this way, we can examine whether any changes in utilization in 2002 represent the effects of a slow-moving relative trend or a sharp break when the policy is put in place. If the dynamic model indicates the latter, it suggests that we are not just picking up the dynamic effects of the PPO policy change. ${ }^{13}$

\section{Means}

Table 1 presents the means of the data. We show the mean utilization rate and copayments for each type of utilization for HMOs and PPOs in each year. Once again, we have no pre-period data for the PPO policy change for office visits due to data limitations. Several discontinuities that preview our ensuing difference-in-difference specifications are apparent in these tabulations. First,

auto-correlation and cluster on plan-by-month ( 45 months $x 4$ plans $=180$ clusters) we obtain standard-errors that are similar, though 0\%-20\% smaller, to those obtained from the more conservative GLS procedure.

${ }^{12}$ In addition, we tested the sensitivity of our 2002 policy change results to excluding data from the first 3 months after the 2001 policy change when into effect (February, March, and April of 2001) and found that the results were unaffected by this exclusion

${ }^{13}$ As further confirmation, we also examined data from the Medicare Current Beneficiary Survey, the largest publicly available source of data on medical utilization by Medicare recipients, between 1995 and 2004-a timeframe that predates our analysis by several years, and therefore allows for the examination of differential trends. The supplemental insurance categories reported in the MCBS allow for the identification of Medicare HMOs, but do not distinguish beneficiaries in a Medicare PPO uniquely; this group is therefore contained in the groups labeled Employer Sponsored Insurance (ESI) and Self-Purchased. We found that enrollees in Medicare HMOs and those with ESI and self-purchased supplemental insurance follow similar trends in utilization for total spending, inpatient visits, outpatient visits and prescriptions drugs, as those with employer-sponsored insurance and self-purchased Medigap. These results are available upon request. 
average copayments for an office visit jump from $\$ 0.14$ in 2001 to $\$ 10.11$ in 2002 for the HMOs, while they remain flat at below $\$ 1$ in the (control) PPO plans over time. ${ }^{14}$ Over the same period, average office visits fell by 0.03 per member per month in the HMOs (relative to an increase of 0.07 visits per member per month in the PPOs, which experienced no copayment increase). Thus, the means suggest a differential decline in office visits for HMO members at the time that office visit copayments increased for them.

Average out-of-pocket payments for a prescription drug increased from $\$ 6.93$ in 2000 to $\$ 13.50$ in 2001 for PPOs. Over the same period, average drug utilization rose by 0.09 prescriptions per member per month in the PPOs, relative to an increase of 0.16 prescriptions per member per month in the HMOs, which had not yet experienced a drug copayment increase. These means, then, suggest the possibility of a relative decline in drug utilization resulting from the increased drug copayments for the PPOs in 2001. For the HMO policy change, the means show an increase in prescription drug copayments from $\$ 1.27$ in 2001 to $\$ 7.63$ in 2002 . They also show a decrease of 0.09 prescriptions per member per month in the HMOs between 2001 and 2002, relative to an increase of 0.14 drugs per member per month in PPOs during the same period. Once again, the means suggest a relative decline in drug utilization resulting from the increased drug copayments for the HMOs in 2002.

Finally, we show means for hospitalizations for each year and type of plan. All hospitalization rates in Table 1 and in later regression tables are multiplied by 10,000, in order to make the numbers easier to read. Hospitalization rates increase over time for both types of plans

\footnotetext{
${ }^{14}$ The fact that the average copays in our data are not precisely $\$ 0$ for the HMOs in 2001 or for the PPOs throughout the sample period may reflect the fact that some of the encounters that we identify as "office visits" were misclassified or it may reflect some minor misreporting of copayments in the data.
} 
throughout the sample period, presumably reflecting the aging of our panel. Table 1 does not suggest an obvious increase or decrease in hospitalizations associated with the policy changes

\section{Part III: Basic Results}

Office Visits

We begin our analysis by examining the effect of the 2002 copayment increase on office visits in the HMOs. This policy change increased copayments from a base of $\$ 0$ to $\$ 10$ for those in the supplemental plan. The results of our analysis are shown in Table 2. Each cell reports a coefficient and standard error (in parentheses).

The first column shows the basic difference-in-difference estimate of the impact on copayments per visit. The statistically significant coefficient of 10.06 is virtually identical to the $\$ 10$ increase that we expect.

The second column of the table shows the difference-in-difference estimate of the impact on office visit utilization. There is a sizeable and highly statistically significant reduction of 0.132 office visits per member per month. Relative to the pre-period mean of 0.753 , this is a $17.5 \%$ decline in office visits. While this appears to be a large response to a $\$ 10$ increase in copayments, it is important to note that the $\$ 10$ increase represents a very large percentage increase in out-ofpocket costs for patients, relative to the $\$ 0$ copayment in the pre-policy period. The implied arcelasticity of demand for office visits is -0.10 , which is quite similar to the arc-elasticities produced 
by the RAND HIE for the non-elderly. ${ }^{15}$ Keeler and Rolph (1988) report arc-elasticities for outpatient services that ranged from -0.17 to -0.31 . Our arc-elasticities for office visits are, therefore, slightly lower than - but nonetheless strikingly similar to - the HIE's arc-elasticities for similar service types.

The third column explores the dynamic pattern of coefficients by showing the effects for each of the three quarters before, the quarter of, and all quarters after the policy change; the results are shown graphically in Figure 1. All coefficients for the dynamic model are measured relative to the omitted quarter, which is 2 quarters prior to the policy change. There is a large rise in office visits in the quarter before the policy change, which presumably reflects anticipation of the change, and then a large and immediate drop in utilization in the quarter after the policy change. This graph clearly suggests a causal impact of the copayment increase itself, and not a spurious trend in utilization.

Much of the large rise immediately before and fall immediately after the copayment change likely represents a one-time shift in the timing of office visits, and not a fundamental change in utilization patterns in response to this higher patient cost. Thus, in the last column of the table, we show the difference-in-difference estimate excluding the quarters immediately before and after the policy change (the estimated change in copayments is almost identical when we excluded these quarters). There is a sizeable decline in the coefficient on office visits to -0.095 , although it remains highly significant. The implied arc-elasticity is -0.07 . We will use this specification as our baseline for the remaining results on office visits.$$
\left(Q_{2}-Q_{1}\right)
$$$$
{ }^{15} \text { Following Keeler and Rolph (1988), arc-elasticities are calculated as } \frac{\left(Q_{2}-Q_{1}\right) /\left(Q_{1}+Q_{2}\right) / 2}{\left(P_{2}-P_{1}\right) /\left(P_{1}+P_{2}\right) / 2} \text {. }
$$$$
\left(P_{1}+P_{2}\right) / 2
$$ 


\section{Prescription Drugs}

There were large increases in copayments for prescription drugs in both 2001 (for PPOs) and 2002 (for HMOs), as described earlier. Unlike physician office visits, however, the exact magnitude of the copayment change for each member depends on the mix of drugs they use, as the copayments changed differently for different types of drugs.

Table 3 shows estimated effects for the 2001 and 2002 policy changes. The effects of these changes on copayments per drug are shown in columns 1 and 5, respectively. For the 2001 policy change, we estimate a $\$ 7.25$ rise in average copayment. For the 2002 policy change, the estimated change in out-of-pocket charges is slightly smaller at $\$ 6.74$. However, these first stage estimates confound two effects: the static effect of rising copayments, holding constant the pre-policy mix of drugs, and the dynamic effect of consumers shifting to less expensive drugs in response. We believe that the correct first stage estimate would include only the first, static part of this response and ignore the second portion. To estimate this static copayment change, we measure utilization in the pre-policy period, multiply by both old and new copayments, and calculate the difference in copayments for this fixed set of drugs. Using this methodology, we get larger estimates of the copayment increases -- $\$ 8.06$ for the 2001 change and $\$ 7.26$ for the 2002 change.

The effects of these changes on the number of prescriptions are shown in the next columns (columns 2 and 6), using the basic difference-in-difference specification. In each case, there is a negative and significant effect on the average number of prescriptions filled. For PPO enrollees in 2001 , there is a reduction in prescriptions filled of 0.110 per member per month, relative to the pre- 
policy mean of 1.97 . There is an $\$ 8.06$ rise in average copayments in 2001 , relative to a pre-policy mean of $\$ 6.93$. This implies an arc-elasticity of approximately -0.08 of drug utilization with respect to its patient cost. For HMO enrollees in 2002 , there is a reduction in prescriptions filled of 0.276 , relative to the pre-period mean for that group of 1.39 . There is a $\$ 7.26$ rise in copayments for this population, relative to a pre-policy mean of $\$ 1.28$. This implies an arc-elasticity of -0.15 , which is quite similar to the arc-elasticity of demand for prescription drugs in 2001 , to the arc-elasticity of demand for office visits and, again, to the arc-elasticities obtained from the RAND HIE for the nonelderly. ${ }^{16}$

The dynamics of these responses are reported in columns 3 and 7 in Table 3 and are shown graphically in the two panels of Figure 2. The results clearly indicate that there were no preexisting trends towards less drug use. Thus, the estimated utilization decline appears to be a causal impact of the policy change. For the 2001 change, however, we once again see that there is an anticipation effect in the quarter before the policy change. To avoid such timing effects, we again drop the quarter before and after the policy change, and show the results in Columns 4 and 8 of Table 3. ${ }^{17}$ In the case of the 2001 policy change, the estimated effect decreases by just over a half, so that the implied arc-elasticity falls to only -0.03 .

Our experiment also allows us to explore the behavioral response to different types of drugs. By assembling a panel of three practicing physicians and two pharmacists, we classified each drug

\footnotetext{
${ }^{16}$ Using the alternative estimates of the copayment increase, which incorporate both the static and dynamic effects of policy change, the implied elasticities remain -0.08 for the 2001 policy change and -0.15 for the 2002 policy change. Therefore, the use of the more sophisticated (and correct) method of estimating copayment changes does not substantively alter our results.

${ }^{17}$ If HMO enrollees began stockpiling prescription drugs as much as 8 months prior to the January 2002 policy change (because the decision to increase copayments was made in April of 2001), we would see this behavior in dynamic graphs estimated at the quarterly level (which are reported in the paper in Figure 2, Panel B). In none of the pre-treatment quarters do we find evidence of significant increases in utilization, as would be the case if drugs were being stockpiled.
} 
into one of three categories: ${ }^{18}$ (1) Acute care drugs are those that, if not taken, will increase the probability of an adverse health event within a month or two (examples are anticonvulsants, antimalarials and anti-angials, coronary vasodilators and thrombolytics). (2) Chronic care medications are designed to treat more persistent conditions that, if not treated, will result in a potentially adverse health event within the year (examples include analgesics, antivirals, ACE inhibitors, antigout medications, beta-blockers, hypertension drugs, statins, and glaucoma medications). The final category includes medications which, while necessary to improve the quality of life, will not result in an adverse health event if not taken, by virtue of their providing symptom relief as opposed to affecting the underlying disease process (examples are acne medications, antihistamines, motion sickness medications, cold remedies, relief of pain drugs). ${ }^{19}$ Each category contained a mix of drugs from the various formulary tiers, so the specific elasticities, by themselves, are not entirely informative. However, we found substantial responsiveness for all three types of drugs, suggesting that members decreased their use of drugs that, according to our expert panel, were likely preventing short-term and long-term adverse health events.

\section{Hospital Utilization}

As highlighted above, a major concern with increased patient cost-sharing is the so-called "offset effect": by raising the cost of going to the doctor or filling prescriptions, and therefore reducing physician or drug use, increased cost-sharing may delay necessary care and increase

\footnotetext{
${ }^{18}$ Consistent with the clinical literature on expert physician panels, our panel exhibited considerable variance of opinion, especially in the distinction between acute and chronic care drugs. We classified a drug as belonging to a certain class if the majority of experts believed that it was in that class. During their deliberations, our panels had access to the Physician Desk Reference and the internet to inform their choices.

${ }^{19}$ We also examined a simpler classification based on the work Tambyn et. al (2001). This approach classifies drugs based on whether a drug was "essential" or not. This classification, however, excludes many drugs with uncertain classification (for example,
} 
hospitalizations. Indeed, the fact that individuals in our sample decreased utilization, even for drugs that were classified as "acute care" by our panel of experts (or "essential" by Tamblyn et al. (2001)), increases this concern. The RAND HIE found no evidence for such offset effects, but there has been little subsequent investigation of this question, particularly for the elderly. This policy change provides an excellent laboratory for testing for such offset effects, in response to reduced prescription drug utilization (in 2001) and in response to both reduced office visits and reduced prescription drug utilization (in 2002).

We explore the effect of both policy changes on hospital utilization in Table 4. The difference-in-difference estimates of the impact of the two policy changes on hospital utilization are shown separately in columns 1 and 4 . Interestingly, both coefficients are positive, although only that for the 2002 policy change is statistically significant. For the 2002 policy change, we find an increase in the probability of any hospital days during the month of $0.078 \%$, relative to the prepolicy mean of $1.30 \%$, or a rise of $6.0 \%$. As the dynamic results show, both in Table 4 and graphically in Figure 3, these effects do not appear to reflect pre-existing trends. However, the coefficients for the 2001 changes are small and statistically insignificant. The larger response in 2002 may be due to the rise in office visit copayments under the HMO plans and the larger reduction in prescription drug use. These results suggest some potential "offset" effect of the changes in coverage for physician and prescription services, in contrast to the RAND HIE. The finding of such an offset effect in the short run is quite striking, and it is likely that any offset effect would operate more strongly over time. But this short run effect is not implausible, as we discuss in Part IV below, which further explores the nature of this offset effect and its implications for 
insurance design.

\section{Summary}

To summarize our basic results, we have found that there is clear price responsiveness for the elderly to coinsurance for both physician visits and prescription drugs, with implied arcelasticities that are similar to those of the RAND HIE. We also found evidence of an "offset effect" of higher coinsurance in terms of increased hospitalizations. This offset effect may mitigate any costs savings from lower office visit or drug utilization; the magnitude of such an offset is explored below.

\section{Part IV: The Offset Effect}

Perhaps the most striking finding from our analysis thus far is the strong evidence of an offset effect in 2002, with hospital visits rising as office visit and prescription drug utilization falls. In this section, we explore this effect further by moving from utilization measures to our (imputed) payment measures. All of the results presented below exclude the quarters before and after the policy change; this exclusion lowers the response of physician visits in 2002, but has no effect on either prescription drug or hospitalization estimates. It is important to recall that our payment information is not measured directly in our data but rather is imputed, so that our conclusions about payment results are somewhat more uncertain than our utilization conclusions.

\section{Quantifying the Offset}

The results of this exercise are presented in the first panel of Table 5, which presents the 
same difference-in-difference regressions as in the earlier tables, but replacing utilization measures with expenditures. For physician visits, we find a decline in imputed expenditures of $\$ 13.16$, which is $14.1 \%$ of the base cost of $\$ 93.25$ per person per month. This effect is similar to the $12.6 \%$ effect that we found using visit counts. For prescription drugs, we find a reduction in payments of $\$ 23.06$ for the 2002 policy change, which is $32 \%$ of the base spending on drugs. Thus, in total, we find a reduction in office visit plus prescription drug payments of $\$ 36.22$ for the 2002 policy change. At the same time, we find an increase in hospitalization payments of $\$ 7.23$, which is $5.4 \%$ of baseline hospital expenditures. These results suggest that increases in hospital spending offset $20 \%$ of the savings from higher copayments on physicians and prescription drugs. While this offset is sizeable, it is unlikely to be enough to reverse any conclusions about the efficacy of copayment changes.

\section{Payer-Specific Offsets and the Fiscal Externality of Supplemental Insurance}

Importantly, however, this offset does not operate equally for all payers. The next panel of Table 5 divides these responses into payments by Medicare and payments by the CalPERS supplemental insurance plans. Medicare, in this time period, did not cover prescription drugs, so the only effects on the Medicare program are lower physician costs and higher hospital costs.

The results of this division by payer are quite interesting. The physician savings accrue roughly equally to Medicare and to CalPERS, despite the fact that Medicare pays $80 \%$ of the charges for physician visits and CalPERS pays only 20\%. This is because CalPERS obtains all the benefit from the shifting of payments from insurer to patient, while Medicare obtains only $80 \%$ of the savings from lower physician utilization (with CalPERS also getting the rest). Thus, when the HMOs introduce the $\$ 10$ physician copayment, there is a total reduction in spending on physicians 
of $\$ 13.16$, of which Medicare receives roughly $80 \%(0.8 * \$ 13.16=\$ 10.53)$. Meanwhile, CalPERS obtains the other $20 \%$ of savings from reduced utilization $(0.2 * 13.16=\$ 2.63)$, plus the transfer of costs from the supplemental insurance plans to patient ( $\$ 10$ per visit, with an average of 0.86 visits per enrollee per month, equals $\$ 8.60)$, for a total of $\$ 11.23$.

The savings from reduced prescription drug utilization, of course, accrue totally to CalPERS. These savings are equal to the total reduction in dollars spent on prescription drugs, plus the cost-shift from CalPERS to enrollees through the increased copayments. At the same time, Medicare bears most of the increased cost of hospitalizations. Of the $\$ 7.23$ in extra hospital costs, Medicare pays $\$ 5.58$, and CalPERS pays only $\$ 1.49$. Thus, on net, Medicare saves $\$ 10.53$ on physician visits, but pays $\$ 5.58$ more in hospitalization costs, so that the offset effect for the Medicare program in isolation is $53 \%$. At the same time, the offset for CalPERS is close to zero, since CalPERS pays relatively little of the hospital costs but receives half of the savings in physician visits and all of the savings on prescription drugs. Thus, while the offset is small overall, it is a major consideration for the Medicare program.

\section{Heterogeneity in Offset}

While this overall offset effect is fairly modest, there is heterogeneity in the offset that has important implications for insurance design. Table 6 divides our sample in five ways to explore heterogeneity by type of enrollee: by income (terciles of the income distribution, based on zip code median income); by age ( 65 to 74,75 to 84 , and 85 and older); by intensity of spending in 2000 (terciles of the overall spending distribution in the period before any policy changes); by Charlson index (a measure of patient health described below); and by categories of chronic illness (described 
further below).

Table 6 has panels for each of these types of heterogeneity, with rows for each category within the type. The first three columns show the results for spending on office visits, prescription drugs, and hospitalizations. The fourth column shows the total offset effect, calculated directly from these first three columns. The fifth and six columns show the offset effect for Medicare and CalPERS, respectively, which are calculated from payer-specific spending regressions. These regressions are not shown, but follow exactly the same pattern as in Table 5: increases in hospital spending accrue about $80 \%$ to Medicare and $20 \%$ to CalPERS; reductions in prescription drug spending accrue completely to CalPERS (and are higher than reductions in total drug spending due to the cost shift from enrollees).

The first panel shows results by income tercile. Here we find that there are relatively flat effects across income groups. The effect on hospitalizations is somewhat smaller for the highest income tercile, and the effect on prescription drug utilization somewhat larger, so that the offset declines with income. None of these differences, however, are statistically significant. Thus, there is little heterogeneity by income.

The results by age, however, suggest more heterogeneity. As age increases, we find similar or even smaller effects on physician and prescription drug spending - but much larger effects on hospital spending. As a result, the implied offset is less than $20 \%$ for those $65-74$, but over $40 \%$ for those 85 and older. For the Medicare program in isolation, there is a 70\% offset for those 75-84, and an offset well above $100 \%$ (i.e. Medicare is losing money from this policy change) for those in the oldest group. Once again, however, the hospital results are relatively imprecise across age groups, so that these differences are not statistically significant. 
The results by (ex-ante) spending tercile are even more striking. There is relatively little variation in physician spending effects by tercile, and a rising reduction in prescription drug spending by tercile. Most striking, however, is the hospitalization effect: the effect is negative for the first tercile, small and positive for the second tercile, and very large for the third tercile, implying that hospital spending rose by $\$ 23$ per enrollee per month as a result of this policy. Overall, there is an offset of almost $50 \%$ for the top tercile of spenders: for every dollar society saves in prescription and physician spending, hospitalization costs increase by 45 cents. Unsurprisingly, this implies an enormous offset for the Medicare program in isolation: the Medicare program loses $\$ 1.19$ in increased hospitalization expenditures for each $\$ 1$ in physician spending savings.

These results are echoed in the findings for the Charlson index, which we divide into three categories. The Charlson index is a weighted sum of indicators for the presence of certain conditions, where the weights reflect relative increases in one-year mortality risk for a person; mortality risk increases with the index. To calculate the index, we use diagnosis codes from each individual's claims history to identify the presence of each of 19 conditions, and then apply the weights described in Charlson et al. (1987). We then run regressions separately for individuals with Charlson indices of 0 (i.e. individuals with none of the conditions), 1-3, and 4 or greater. We find a modest increase, in absolute value, in the physician and prescription drug effects by Charlson index, but the differential effect on hospital spending is even more striking. Indeed, the hospital spending effect is enormous for those who are unhealthiest by this measure, with hospital spending increasing by almost $\$ 2$ for every $\$ 1$ saved on other spending - and Medicare's hospital spending increasing by more than $\$ 6$ for every $\$ 1$ saved on physician spending! 
Finally, the last panel in the table explores the findings by chronic illness. Again, we use the diagnosis codes from each individual's claims history to identify individuals who suffer from each of seven chronic illnesses. ${ }^{20}$ We then run regressions separately for the sub-samples with and without chronic illnesses. The first two rows compare those with any of the seven chronic illnesses to those with none of the chronic illnesses. In each category the effects are much larger for those with any chronic illness. Yet the most striking difference is in hospitalization effects; there is no effect on hospital payments for those with no chronic illness, while there is an $\$ 18.25$ per person per month increase in hospitalization payments for those with chronic illness. Overall, for those with chronic illness, there is a roughly $43 \%$ offset; for the Medicare program in isolation, the offset is over $100 \%$.

The remaining rows of the table consider each of the seven chronic illnesses separately. The results vary across type of illness, with particularly large offsets for those with hypertension, diabetes, arthritis, and affective disorders, and relatively little offset for those with hypercholesterol, asthma, and gastritis. In no category does the overall offset approach one; that is, in every single case, the overall medical system saved money when CalPERS raised copayments. But in many cases, the Medicare program was a significant loser: the most striking case is affective disorders, where most of the savings are on prescription drugs, so that Medicare is losing almost $\$ 8$ in increased hospitalization spending for each $\$ 1$ it is saving on prescription drugs.

\section{Plausibility}

A major concern with all of these results is the plausibility that such a large effect on hospitalizations could arise so quickly after changes in physician and prescription drug copayments.

\footnotetext{
${ }^{20}$ Our chronic illness definitions follow Goldman et al. (2004).
} 
We address that concern in four ways. First, we note that two other prominent papers have reported substantial effects of decreased use of prescription drugs on adverse events. Neither paper has a strictly defined control group (in the first, identification is cross-sectional and, in the second, identification is over time), but their results are consistent with our findings. Hsu et al. (2006) find that Medicare beneficiaries whose pharmacy benefits were subject to a cap had 13 percent higher (non-elective) hospitalizations and 22 percent higher death rates than beneficiaries whose benefits were not capped. Among patient who used drugs for hypertension, hyperlipidemia, or diabetes, nonelective hospitalizations increased by 27 percent, and deaths by 33 percent. Tamblyn et.al (2001) find that the rate of emergency department hospitalizations for the elderly, increased by 14.2 per 10,000 patient-months in the 17 months after patient cost-sharing was instituted.

Second, since the offset effect is concentrated among those with chronic illness, we extended our analysis of prescription drug responses to examine the use of prescription drugs that are specific to each individual's chronic condition. These disease-specific drugs represent a direct channel to increasing the risk of hospitalization for the chronically ill. By assembling a team of physicians and pharmacists, ${ }^{21}$ we identified the classes of drug that would be most relevant to the treatment of each chronic condition (e.g. statins for high cholesterol; antacids, acid blockers, and proton pump inhibitors for gastritis). If the increased hospitalizations among the chronically ill were caused by decreased management of their chronic illness through prescription drugs, we would expect to see a decline in the use of drugs that are specific to the chronic condition. Indeed, for those with any chronic illness, we find that about $40 \%$ of the decrease in prescription drugs comes in the form of drugs that are intended to treat the chronic illness. This finding increases our

\footnotetext{
${ }^{21} \mathrm{We}$ are grateful to the three internists/generontologists at Dartmouth Medical School, and the two at Harvard Medical School, who assisted us in this effort.
} 
confidence that the increase in hospitalizations among the chronically ill could be driven by a decline in management of their chronic illness.

Third, recall from our earlier discussion that these policy changes led to a statistically significant decrease in use of "acute care" drugs; these drugs included those medications that, if not taken, could lead to an adverse health event within a month or two. After finding the results reported in this paper, we asked a subset of our physician panel (comprising the 3 physicians who were internists and gerontologists) as well as two new physicians where this effect would be greatest, and they reported that it would be mostly likely to operate quickly for those with diabetes and hypertension, and less so for asthma, because the decreased use for asthma patients would largely reflect reduced use of anti-histamines. While these interviews constitute informal evidence, they are generally quite consistent with the findings in Table 6 of our paper, which show statistically significant increases in hospital payments for individuals with hypertension and diabetes, but statistically insignificant increases for individuals with asthma.

Finally, we note that the hospital offset effect that we find actually implies a rather modest direct offset between reduced office visit/drug utilization and increased hospitalization. For example, our baseline hospitalization result in column 6 of Table 4 reflects only 7 additional hospitalizations per month per 10,000 members. In comparison, the coefficients from the office visit and prescription drug regressions suggest 950 fewer monthly office visits per 10,000 members and 2,610 fewer monthly prescription drug purchases per 10,000 members. Even if only diseasespecific drug utilization matters, this implies that a reduction in monthly prescription drug purchases of roughly 700 leads to 7 more hospitalizations per 10,000 members. Only in rare cases, then, does the decreased use of office visits and prescription drugs translate into a hospitalization. 
In addition, it is worth noting that the magnitude of our estimated hospitalization effects are consistent with Tamblyn et al. (2001), which reports that a reduction of 1700 "essential" drugs per 10,000 members is associated with an increase of 7 adverse events (including acute care hospital admissions, long-term care admissions, and death) and 14 emergency department visits per 10,000 member-months.

\section{Part V: Conclusions and Implications}

The rapid rise in both the share of our population that is elderly, and the spending per elderly person, has placed pressure on both public and private insurers to find new ways to control medical costs in this population. A number of approaches have been suggested, but forefront among them is increased consumer cost-consciousness. While Medicare has relatively high copayments and deductibles, these "holes" are filled by supplementary insurance for most elderly. Thus, the elderly typically face very low copayments on most medical utilization.

Our results show that higher copayments for office visits and prescription drugs can have a real effect in terms of reducing medical spending by the elderly. The effects are large in absolute terms, suggesting that moving from a $\$ 0$ to a $\$ 10$ copayment led to a $20 \%$ reduction in physician visits, and that a roughly $\$ 7$ copayment rise, on average, reduced prescription drug use by $20 \%$. Because the percentage increases in copayments were large, however, the implied arc-elasticities are similar to those reported in the RAND HIE for the non-elderly.

Most interestingly, we document the first convincing evidence for an offset effect of higher copayments. While previous work has conjectured that such an offset might be present, the only convincing evidence, from the RAND HIE, rejected the notion of an offset, suggesting instead that 
physician and hospital care were complements. Overall, we find a rather modest offsetting rise in hospital care when physician and prescription drug copayments are raised. But we find substantial offsets for the sickest populations with chronic diseases, suggesting that, for chronically ill populations, there is little financial gain to higher copayments.

These findings have several important implications for optimal health insurance design.. The first is that the fiscal externality associated with supplemental insurance coverage, which has been the subject of much policy discussion, may be more modest than originally presumed. This is because the increase in physician and drug spending arising from supplemental coverage is substantially offset (for the Medicare program) by the fall in hospital costs.

Second, the results from RAND clearly implied that optimal health insurance would feature high patient coinsurance up to an income-related out-of-pocket limit. Our findings qualify that result, suggesting further that optimal insurance would be tied to underlying health status, with chronically ill patients facing lower cost-sharing. The cost-sharing increases in our data were sufficiently modest that income-related out-of-pocket limits alone would not accomplish this goal, so specific targeting of copayments may be required.

Finally, our findings have implications for the design of Medicare's new prescription drug benefit. One of the most controversial features of Medicare's new prescription drug benefit is the so-called "doughnut hole": the gap in prescription drug coverage for beneficiaries with total drug costs that exceed $\$ 2,250$ per year, until their drug costs exceed $\$ 5,100$ per year. Our results suggest that this "doughnut hole," by increasing coinsurance rates to $100 \%$ for some of the most chronically ill Medicare beneficiaries, could increase Medicare's costs. In particular, those beneficiaries who are affected by the "doughnut hole" are likely to be similar to the chronically ill sub-populations 
where we found that increased Medicare hospital spending exceeded any savings from reduced prescription drug and office visit utilization. Future research should carefully explore the full system-wide implications of this design feature of the Part D program. 


\section{References}

Atherly, Adam (2001). “Supplemental Insurance: Medicare’s Accidental Stepchild," Medical Care Research and Review 58:2: 131-161.

Board of Trustees, Federal Hospital Insurance and Federal Supplementary Medical Insurance Trust Funds (2005), 2005 Annual Report of the Board of Trustees of the Federal Hospital Insurance and Federal Supplementary Medical Insurance Trust Funds, 23 Mar 2005.

Bertrand, Marianne, Esther Duflo, and Sendhil Mullainathan (2004), "How Much Should We Trust Differences-in-Differences Estimates?," Quarterly Journal of Economics 19:1, 249-275.

CalPERS (2000). "PERSCare and PERSChoice: The Road to Financial Recovery," available at http://www.calpers.ca.gov/health/plan/care-choice/PERSCareChoice.pdf.

CalPERS (2006). "Facts at a Glance," available at http://www.calpers.ca.gov/eip-docs/about/facts/health.pdf

Center for Medicaid and Medicare Services (2005), National Health Expenditures, available at www.cms.hhs.gov/NationalHealthExpendData/04_NationalHealthAccountsAgePHC.asp.

Charlson ME, Pompei P, Ales KL, McKenzie CR (1987). A new method of classifying prognostic comorbidity in longitudinal studies: development and validation. J Chronic Disease 40(5): 373-383.

Cherkin, Daniel, Louis Grothaus and Edward Wagner (1989). "The Efect of Office Visit Copayments on Utilization in a Health Maintenance Organization," Medical Care 27, 10361045.

Christensen, Sandra, Stephen H. Long, Jack Rodgers (CBO) (1987), “Acute Health Care Costs for the Aged Medicare Population: Overview and Policy Options," The Milbank Quarterly 65(3): pp. 397-425.

Congressional Budget Office (2007), Budget Options, available at www.cbo.gov/publications/.

Eichner, Matthew (1996). "Incentives, Price Expectations and Medical Expenditures: An Analysis of Claims Under Employer-Provided Health Insurance," mimeo, MIT.

Ettner, Susan (1997). "Adverse Selection and the Purchase of Medigap Insurance by the Elderly," Journal of Health Economics 16, 543-562.

Feldstein, Martin (1971). "Hospital Cost Inflation: A Study of Non-Profit Price Dynamics," American Economic Review 61, 1681-1702. 
Finkelstein, Amy (2007). "The Aggregate Effects of Health Insurance: Evidence from the Introduction of Medicare," Quarterly Journal of Economics, February..

Gaynor, Martin, Jian Li, and William B. Vogt (2007) "Substitution, Spending Offsets, and Prescription Drug Benefit Design," Forum for Health Economics \& Policy: Vol. 10: Iss. 2 (Prescription Drug Insurance), Article 4.: http://www.bepress.com/fhep/10/2/4

Goldman, Dana P., Geoffrey F. Joyce, Jose J. Escarce, Jennifer E. Pace, Matthew D. Colomom, Marianne Laouri, Pamela B. Landsman, and Steven M. Teutsch (2004). "Pharmacy Benefits and the Use of Drugs by the Chronically Ill," Journal of the American Medical Association 291, 2344-23501.

Goldman, Dana, Geoffrey Joyce and Pinar Karaca-Mandic (2006). "Varying Pharmacy Benefits With Clinical Status: The Case of Cholesterol-Lowering Therapy," American Journal of Managed Care, 12, 21-28.

Goldman, Dana and Tomas Philipson (2007). "Integrated Insurance Design in the Presence of Multiple Medical Technologies," American Economic Review, forthcoming.

Hsu, John, Mary Price, Jie Huang, Richard Brand, Vicki Fung, Rita Hui, Bruce Fireman, Joseph P. Newhouse, and Joseph V. Selby (2006). "Unintended Consequences of Caps on Medicare Drug Benefits," New England Journal of Medicine 354: 2349-2359.

Hurd, Michael and Kathleen McGarry (1997). "Medical Insurance and the Use of Health Care Services by the Elderly," Journal of Health Economics 16, 129-154.

Johnson, Richard E., Michael J. Goodman, Mark C. Hornbrook, and Michael B. Eldredge (1997). "The Impact of Increasing Patient Prescription Drug Cost Sharing on Therapeutic Classes of Drugs Received and on the Health Status of Elderly HMO Members," Health Services Research 32(1): 103-122.

Keeler, Emmett B. and John E. Rolph (1988). "The Demand for Episodes of Treatment in the Health Insurance Experiment," Journal of Health Economics 7: 337-367.

Landsman, Pamela B., Winnie Yu, XiaoFeng Liu, Steven M. Tuetsch, and Mark L. Berger (2005). "Impact of 3-Tier Pharmacy Benefit Design and Increased Consumer Cost-Sharing on Drug Utilizaiton," American Journal of Managed Care 11: 621-628.

Lillard, Lee and Jeanette Rogowski (1995). "Does Supplemental Private Insurance Increase Medicare Costs?," RAND Labor and Population Program Working Paper 95-16.

Lillard, Lee, Jeanette Rogowski and Raynard Kington (1999). "Insurance Coverage for Prescription Drugs: Effets on Use and Expenditures in the Medicare Population," RAND Labor and Population Program Working Paper 99-09. 
Manning, Willard G., Joseph P. Newhouse, Naihua Duan, Emmett B. Keeler, and Arleen Leibowitz (1987). "Health Insurance and the Demand for Medical Care: Evidence from a Randomized Experiment," The American Economic Review 77(3): 251-277.

McCall, Nelda, Thomas Rice, James Boismier and Richard West (1991). "Private Health Insurance and Medical Care Utilization: Evidence from the Medicare Population," Inquiry 28, 276287.

McGuire, Thomas (1991). "Paralyzing Medicare's Demand-Side Policies,” in: Frech III, H.E. (Ed.), Regulating Doctors' Fees: Competition, Benefits and Controls Under Medicare. AEI Press, Washington, D.C., pp. 174-192.

Newhouse, Joseph (1993). Free for All: Lessons from the RAND Health Insurance Experiment. Cambridge, MA: Harvard University Press.

Phelps, Charles and Joseph Newhouse (1972). "Effects of Coinsurance: A Multivariate Analysis," Social Security Bulletin 35, 20-29.

Rice, Thomas and Karen Y. Matsuoka (2004). "The Impact of Cost-Sharing on Appropriate Utilization and Health Status: A Review of the Literature on Seniors," Medical Care Research and Review 61(4), 415-452.

Rossett, Richard N. and Lien-fu Huang (1973). "The Effect of Health Insurance on the Demand for Medical Care," Journal of Political Economy 81, 281-305.

Selby, Joe, Fruce Fireman, and Bix Swain (1996). "Effect of a Co-payment on use of the Emergency Department in a Health Maintenance Organization," New England Journal of Medicine 334, 635-641.

Tamblyn, Robyn, et. al (2001). "Adverse Events Associated With Prescription Drug Cost-Sharing Among Poor and Elderly Persons," JAMA 285(4), 24/31 January 2001, 421-429.

Wolfe, John and John Goodeeris (1991). "Adverse Selection, Moral Hazard and Wealth Effects in the Medigap Insurance Market,” Journal of Health Economics 10, 433-459. 
Table 1: Means of Key Dependent Variables

By Type of Plan and Year

\begin{tabular}{|c|c|c|c|c|c|c|c|c|}
\hline & \multicolumn{4}{|c|}{ PPOs } & \multicolumn{4}{|c|}{ HMOs } \\
\hline & \multirow{2}{*}{$\begin{array}{c}\begin{array}{c}\text { Pre- } \\
\text { policy }\end{array} \\
2000 \\
\end{array}$} & \multicolumn{3}{|c|}{ Post-policy } & \multicolumn{2}{|c|}{ Pre-policy } & \multicolumn{2}{|c|}{ Post-policy } \\
\hline & & 2001 & 2002 & 2003 & 2000 & 2001 & 2002 & 2003 \\
\hline $\begin{array}{l}\text { Office Visits } \\
\text { Average } \\
\text { copayment per } \\
\text { visit (in dollars) }\end{array}$ & - & $\$ 0.68$ & $\$ 0.61$ & $\$ 0.59$ & - & $\$ 0.14$ & $\$ 10.11$ & $\$ 9.89$ \\
\hline $\begin{array}{l}\text { Visits per } \\
\text { member per } \\
\text { month }\end{array}$ & - & 1.07 & 1.14 & 1.19 & - & 0.75 & 0.72 & 0.75 \\
\hline $\begin{array}{l}\text { Prescription } \\
\text { Drugs }\end{array}$ & & & & & & & & \\
\hline $\begin{array}{l}\text { Average } \\
\text { copayment per } \\
\text { drug (in dollars) }\end{array}$ & $\$ 6.93$ & $\$ 13.50$ & $\$ 13.82$ & $\$ 13.29$ & $\$ 1.36$ & $\$ 1.27$ & $\$ 7.63$ & $\$ 7.43$ \\
\hline $\begin{array}{l}\text { Drugs per } \\
\text { member per } \\
\text { month }\end{array}$ & 1.98 & 2.07 & 2.21 & 2.44 & 1.27 & 1.43 & 1.34 & 1.50 \\
\hline Hospitalizations & & & & & & & & \\
\hline $\begin{array}{l}\text { Share of } \\
\text { members with } \\
\text { any hospital days } \\
\text { during the month } \\
(\mathrm{x} 10,000)\end{array}$ & 156.7 & 169.8 & 182.2 & 206.7 & 119.5 & 131.0 & 149.0 & 174.3 \\
\hline
\end{tabular}


Table 2: Effects of 2002 HMO Office Visit Copayment Increase On Office Visit Utilization

\begin{tabular}{|c|c|c|c|c|}
\hline \multirow[t]{2}{*}{$\begin{array}{l}\text { Independent } \\
\text { variable }\end{array}$} & \multirow{2}{*}{$\begin{array}{c}\text { Copayment } \\
\text { (dollars per drug) } \\
\text { (1) }\end{array}$} & \multicolumn{3}{|c|}{$\begin{array}{l}\text { Utilization } \\
\text { (Number of office visits per member per month) }\end{array}$} \\
\hline & & (2) & (3) & (4) \\
\hline HIPAY & $\begin{array}{c}\$ 10.06 * * \\
(0.05)\end{array}$ & $\begin{array}{c}-.132 * * \\
(.018)\end{array}$ & & $\begin{array}{c}-.095 * * \\
(.012)\end{array}$ \\
\hline HIPAY $_{t-4}$ & & & $\begin{array}{c}.016 \\
(.018)\end{array}$ & \\
\hline HIPAY $_{t-3}$ & & & $\begin{array}{l}.0002 \\
(.016)\end{array}$ & \\
\hline HIPAY $_{t-1}$ & & & $\begin{array}{l}.130 * * \\
(.016)\end{array}$ & \\
\hline HIPAY $_{t}$ & & & $-.036 * *$ & \\
\hline HIPAY $_{t+1}$ & & & $\begin{array}{l}-.094 * * \\
(.016)\end{array}$ & \\
\hline HIPAY $_{t+2}$ & & & $\begin{array}{l}-.071 * * \\
(.016)\end{array}$ & \\
\hline HIPAY $_{t+3}$ & & & $-.082 * *$ & \\
\hline HIPAY $_{t+4}$ & & & $\begin{array}{l}-.101 * * \\
(.016)\end{array}$ & \\
\hline HIPAY $_{t+5}$ & & & $\begin{array}{l}-.113 * * \\
(.016)\end{array}$ & \\
\hline HIPAY $_{\mathrm{t}+6}$ & & & $\begin{array}{l}-.029 * * \\
(.016)\end{array}$ & \\
\hline $\mathrm{N}$ & 128 & 128 & 128 & 104 \\
\hline
\end{tabular}

** denotes significance at the $5 \%$ level.

Each column shows coefficients from a different regression; standard errors are reported in parentheses. The dependent variable is indicated on the column heading; the independent variable is indicated on the row label. Regressions control for plan and month fixed effects. They are estimated by GLS, allowing for planspecific autocorrelation and plan-specific heteroskedasticity. Regressions include data from February 2001 through September 2003. Column 4 excludes data from the 3 months before and after the policy change, in order to eliminate the effects from any temporary shifts in the timing of care. 
Table 3: Effects of Drug Copayment Increases On Drug Utilization

\begin{tabular}{|c|c|c|c|c|c|c|c|c|}
\hline \multirow{3}{*}{$\begin{array}{l}\text { Independent } \\
\text { variable }\end{array}$} & \multicolumn{4}{|c|}{2001 Policy Change } & \multicolumn{4}{|c|}{2002 Policy Change } \\
\hline & \multirow{2}{*}{$\begin{array}{c}\text { Copayment } \\
\text { (dollars per } \\
\text { drug) } \\
\text { (1) }\end{array}$} & \multicolumn{3}{|c|}{$\begin{array}{c}\text { Utilization } \\
\text { (Number of drugs per } \\
\text { member per month) }\end{array}$} & \multirow{2}{*}{$\begin{array}{c}\text { Copayment } \\
\text { (dollars per } \\
\text { drug) } \\
(5)\end{array}$} & \multicolumn{3}{|c|}{$\begin{array}{c}\text { Utilization } \\
\text { (Number of drugs per } \\
\text { member per month) }\end{array}$} \\
\hline & & (2) & (3) & (4) & & (6) & (7) & (8) \\
\hline HIPAY & $\begin{array}{c}\$ 7.25^{* *} \\
(0.06)\end{array}$ & $\begin{array}{c}-.111 * * \\
(.020)\end{array}$ & & $\begin{array}{c}-.048 * * \\
(.014)\end{array}$ & $\begin{array}{c}\$ 6.74 * * \\
(0.09)\end{array}$ & $\begin{array}{c}-.276^{* *} \\
(.016)\end{array}$ & & $\begin{array}{c}-.261 * * \\
(.021)\end{array}$ \\
\hline HIPAY $_{t-5}$ & & & $\begin{array}{l}-.030 \\
.034)\end{array}$ & & & & & \\
\hline HIPAY $_{\mathrm{t}-4}$ & & & $\begin{array}{r}-.075^{* *} \\
(.020)\end{array}$ & & & & $\begin{array}{c}.005 \\
(.029)\end{array}$ & \\
\hline HIPAY $_{t-3}$ & & & $\begin{array}{c}-.023 \\
(.021)\end{array}$ & & & & $\begin{array}{c}.016 \\
(.017)\end{array}$ & \\
\hline HIPAY $_{t-1}$ & & & $\begin{array}{l}.093^{* * *} \\
(.021)\end{array}$ & & & & $\begin{array}{l}.039 * * \\
(.017)\end{array}$ & \\
\hline HIPAY $_{t}$ & & & $\begin{array}{r}-.101 * * \\
(.020)\end{array}$ & & & & $\begin{array}{r}-.236 * * * \\
(.016)\end{array}$ & \\
\hline HIPAY $_{t+1}$ & & & $\begin{array}{r}-.073 * * \\
(.020)\end{array}$ & & & & $\begin{array}{c}-219^{* *} \\
(.016)\end{array}$ & \\
\hline HIPAY $_{t+2}$ & & & $\begin{array}{r}-.082 * * \\
(.020)\end{array}$ & & & & $\begin{array}{r}-.220^{* *} \\
(.016)\end{array}$ & \\
\hline HIPAY $_{t+3}$ & & & $\begin{array}{c}-.052 \\
(.034)\end{array}$ & & & & $\begin{array}{r}-.189 * * \\
(.016)\end{array}$ & \\
\hline HIPAY $_{t+4}$ & & & & & & & $\begin{array}{r}-.320 * * \\
(.016)\end{array}$ & \\
\hline HIPAY $_{t+5}$ & & & & & & & $\begin{array}{c}-.312^{* *} \\
(.016)\end{array}$ & \\
\hline HIPAY $_{t+6}$ & & & & & & & $\begin{array}{r}-.269 * * \\
(.016) \\
\end{array}$ & \\
\hline $\mathrm{N}$ & 80 & 80 & 80 & 58 & 124 & 124 & 124 & 100 \\
\hline
\end{tabular}

** denotes significance at the 5\% level.

Each column shows coefficients from a different regression; standard errors are reported in parentheses. The dependent variable is indicated on the column heading; the independent variable is indicated on the row label. Regressions control for plan and month fixed effects. They are estimated by GLS, allowing for planspecific autocorrelation and plan-specific heteroskedasticity. Columns 1-4 include data from January 2000 through November 2001, and Columns 5-8 include data from March 2001 through September 2003. Columns 4 and 8 exclude data from the 3 months before and after the relevant policy change, in order to eliminate the effects of any temporary shifts in the timing of care. 
Table 4: Effects of Copayment Increases on the Probability That a Member Experiences Any Hospital Days During the Month

\begin{tabular}{|c|c|c|c|c|c|c|}
\hline & \multicolumn{3}{|c|}{2001 Policy Change } & \multicolumn{3}{|c|}{2002 Policy Change } \\
\hline & (1) & (2) & (3) & (4) & (5) & (6) \\
\hline HIPAY & $\begin{array}{c}3.69 \\
(2.61) \\
\end{array}$ & & $\begin{array}{l}5.31 * * \\
(2.70)\end{array}$ & $\begin{array}{l}7.79 * * \\
(2.20) \\
\end{array}$ & & $\begin{array}{l}7.16 * * \\
(2.29)\end{array}$ \\
\hline HIPAY $_{\mathrm{t}-5}$ & & $\begin{array}{l}-0.22 \\
(6.83)\end{array}$ & & & & \\
\hline HIPAY $_{\mathrm{t}-4}$ & & $\begin{array}{l}-8.96 \\
(4.33)\end{array}$ & & & $\begin{array}{c}3.79 \\
(5.00)\end{array}$ & \\
\hline HIPAY $_{\mathrm{t}-3}$ & & $\begin{array}{c}4.51 \\
(4.43)\end{array}$ & & & $\begin{array}{l}-4.81 \\
(4.48)\end{array}$ & \\
\hline HIPAY $_{\mathrm{t}-1}$ & & $\begin{array}{l}-4.67 \\
(4.43)\end{array}$ & & & $\begin{array}{l}-4.20 \\
(4.48)\end{array}$ & \\
\hline HIPAY $_{t}$ & & $\begin{array}{l}-4.01 \\
(4.32)\end{array}$ & & & $\begin{array}{l}-0.66 \\
(4.31)\end{array}$ & \\
\hline HIPAY $_{t+1}$ & & $\begin{array}{c}7.10 \\
(4.32)\end{array}$ & & & $\begin{array}{l}8.33 * \\
(4.32)\end{array}$ & \\
\hline HIPAY $_{t+2}$ & & $\begin{array}{c}3.17 \\
(4.32)\end{array}$ & & & $\begin{array}{c}1.09 \\
(4.32)\end{array}$ & \\
\hline HIPAY $_{t+3}$ & & $\begin{array}{l}-0.85 \\
(4.94)\end{array}$ & & & $\begin{array}{c}14.22 * * \\
(4.32)\end{array}$ & \\
\hline HIPAY $_{t+4}$ & & & & & $\begin{array}{c}6.21 \\
(4.32)\end{array}$ & \\
\hline HIPAY $_{t+5}$ & & & & & $\begin{array}{c}4.72 \\
(4.32)\end{array}$ & \\
\hline HIPAY $_{t+6}$ & & & & & $\begin{array}{c}7.00 \\
(4.35) \\
\end{array}$ & \\
\hline $\mathrm{N}$ & 96 & 96 & 72 & 128 & 128 & 104 \\
\hline
\end{tabular}

$* *$ denotes significance at the $5 \%$ level.

$*$ denotes significance at the $10 \%$ level.

Each column shows coefficients from a different regression; standard errors are reported in parentheses. The dependent variable is indicated on the column heading; the independent variable is indicated on the row label. Regressions control for plan and month fixed effects. They are estimated by GLS, allowing for planspecific autocorrelation and plan-specific heteroskedasticity. Columns 1-3 include data from January 2000 through December 2001, and Columns 4-6 include data from February 2001 through September 2003. Columns 3 and 6 exclude data from the 3 months before and after the relevant policy change, in order to eliminate the effects of any temporary shifts in the timing of care. Note that the dependent variable is multiplied by 10,000 . 
Table 5: Effects of 2002 Copayment Increases on Medical Payments Per Member Per Month By Source of Payment

\begin{tabular}{|c|c|c|c|c|}
\hline & \multicolumn{4}{|c|}{2002 Policy Change } \\
\hline & $\begin{array}{c}(1) \\
\text { Office Visit } \\
\text { Payments } \\
\text { (dollars) }\end{array}$ & $\begin{array}{c}\text { (2) } \\
\text { Drug Payments } \\
\text { (dollars) }\end{array}$ & $\begin{array}{c}(3) \\
\text { Hospital } \\
\text { Payments } \\
\text { (dollars) }\end{array}$ & $\begin{array}{c}\text { (4) } \\
\text { Offset } \\
\text { (Percent) }\end{array}$ \\
\hline All Sources & $\begin{array}{c}-13.16^{* * *} \\
(1.18)\end{array}$ & $\begin{array}{c}-23.06^{* *} \\
(1.85)\end{array}$ & $\begin{array}{l}7.23 * * \\
(2.60)\end{array}$ & $20.0 \%$ \\
\hline$\frac{\text { Payment Source: }}{\text { Medicare }}$ & $\begin{array}{c}-10.53^{* *} \\
(0.95)\end{array}$ & -- & $\begin{array}{l}5.58^{* *} \\
(2.25)\end{array}$ & $53.0 \%$ \\
\hline $\begin{array}{l}\text { Supplemental } \\
\text { Insurance }\end{array}$ & $\begin{array}{l}-11.24 \\
(0.26)\end{array}$ & $\begin{array}{c}-29.20 * * \\
(1.67)\end{array}$ & $\begin{array}{l}1.49 * * \\
(0.38)\end{array}$ & $3.7 \%$ \\
\hline $\mathrm{N}$ & 104 & 100 & 104 & \\
\hline
\end{tabular}

** denotes significance at the $5 \%$ level.

$*$ denotes significance at the $10 \%$ level.

Each cell shows the coefficient from a separate difference-in-difference regression; standard errors are reported in parentheses. The dependent variable is indicated on the column heading; the payment source is indicated on the row label. Regressions control for plan and month fixed effects. They are estimated by GLS, allowing for plan-specific autocorrelation and plan-specific heteroskedasticity. All regressions exclude data from the 3 months before and after the relevant policy change, in order to exclude the effects of any temporary shifts in the timing of care. There are 4 fewer observations used for the drug payment regressions, because months that were affected by timing shifts in drug purchases due to other policy changes were excluded. Specifically, the regressions exclude February 2001, due to unusually large, one-time decreases in drug purchases in the PPOs resulting from the February 2001 policy change.

Column 4 shows the increase in hospital payments as a percentage of the decrease in office visit and drug payments. That is, it is equal to [-Column 3/ (Column $1+$ Column 2)]. 
Table 6: Heterogeneity in Effects of 2002 Copayment Increases on Payments per Member per Month, by Type of Plan Member

\begin{tabular}{|c|c|c|c|c|c|c|}
\hline \multirow[b]{2}{*}{ Type of Plan Member } & \multicolumn{3}{|c|}{2002 HMO Policy Change } & \multicolumn{3}{|c|}{2002 Offset Effects } \\
\hline & $\begin{array}{c}(1) \\
\text { Office } \\
\text { Visit } \\
\text { Payments } \\
\text { (Dollars) }\end{array}$ & $\begin{array}{c}\text { (2) } \\
\text { Drug } \\
\text { Payments } \\
\text { (Dollars) }\end{array}$ & $\begin{array}{c}(3) \\
\text { Hospital } \\
\text { Payments } \\
\text { (Dollars) }\end{array}$ & $\begin{array}{c}(4) \\
\text { Total } \\
\text { Offset } \\
\text { (Percent) }\end{array}$ & $\begin{array}{c}(5) \\
\text { Medicare } \\
\text { Offset } \\
\text { (Percent) }\end{array}$ & $\begin{array}{c}(6) \\
\text { Supplemental } \\
\text { Insurance } \\
\text { Offset } \\
\text { (Percent) }\end{array}$ \\
\hline$\frac{\text { Income Tercile: }}{\text { Low Income }}$ & $\begin{array}{c}-11.13^{* *} \\
(1.59)\end{array}$ & $\begin{array}{c}-22.10 * * \\
(1.50)\end{array}$ & $\begin{array}{c}6.16 \\
(6.39)\end{array}$ & $18.5 \%$ & $52.0 \%$ & $3.2 \%$ \\
\hline Middle Income & $\begin{array}{c}-15.07 * * \\
(1.42)\end{array}$ & $\begin{array}{c}-23.65 * * \\
(1.54)\end{array}$ & $\begin{array}{c}7.14 \\
(8.29)\end{array}$ & 18.4 & 41.2 & 5.3 \\
\hline High Income & $\begin{array}{c}-14.03 * * \\
(1.38)\end{array}$ & $\begin{array}{c}-29.76 * * \\
(2.80)\end{array}$ & $\begin{array}{c}4.41 \\
(5.28)\end{array}$ & 9.4 & 33.6 & 1.1 \\
\hline$\frac{\text { Member Age: }}{65-74}$ & $\begin{array}{c}-13.67 * * \\
(1.47)\end{array}$ & $\begin{array}{c}-23.98 * * \\
(1.70)\end{array}$ & $\begin{array}{c}6.81 \\
(4.38)\end{array}$ & 18.1 & 48.4 & 3.3 \\
\hline $75-84$ & $\begin{array}{c}-15.54 * * \\
(1.35)\end{array}$ & $\begin{array}{c}-23.64 * * \\
(2.06)\end{array}$ & $\begin{array}{l}11.07 * \\
(6.65)\end{array}$ & 28.3 & 70.3 & 4.8 \\
\hline $85+$ & $\begin{array}{l}-9.54 * * \\
(2.30)\end{array}$ & $\begin{array}{c}-22.54 * * \\
(2.86)\end{array}$ & $\begin{array}{c}13.96 \\
(19.44)\end{array}$ & 43.5 & 144.0 & 6.9 \\
\hline $\begin{array}{l}\text { Spending Tercile: } \\
\text { Low Spending }\end{array}$ & $\begin{array}{c}-11.08 * * \\
(1.53)\end{array}$ & $\begin{array}{c}-11.69 * * \\
(1.80)\end{array}$ & $\begin{array}{c}-7.95 * * \\
(3.00)\end{array}$ & -34.9 & -83.9 & -3.1 \\
\hline Middle Spending & $\begin{array}{c}-12.59 * * \\
(1.61)\end{array}$ & $\begin{array}{c}-23.40 * * \\
(1.60)\end{array}$ & $\begin{array}{c}7.24 \\
(5.17)\end{array}$ & 20.1 & 54.6 & 3.9 \\
\hline High Spending & $\begin{array}{c}-15.43 * * \\
(1.60)\end{array}$ & $\begin{array}{c}-35.02 * * \\
(2.21)\end{array}$ & $\begin{array}{l}22.63 * * \\
(8.41)\end{array}$ & 44.9 & 119.2 & 6.0 \\
\hline$\underline{\text { Charlson Index: }}$ & $\begin{array}{c}-7.53 * * \\
(0.87)\end{array}$ & $\begin{array}{c}-11.78 * * \\
(1.00)\end{array}$ & $\begin{array}{r}4.34 * * \\
(1.78)\end{array}$ & 22.5 & 61.0 & 2.8 \\
\hline $1-3$ & $\begin{array}{c}-11.05 * * \\
(1.40)\end{array}$ & $\begin{array}{c}-24.24 * * \\
(1.33)\end{array}$ & $\begin{array}{l}12.89 * * \\
(6.08)\end{array}$ & 36.5 & 117.6 & 4.9 \\
\hline $4+$ & $\begin{array}{c}-13.68 * * \\
(2.39)\end{array}$ & $\begin{array}{c}-34.68 * * \\
(2.28)\end{array}$ & $\begin{array}{l}85.93 * * \\
(31.19)\end{array}$ & 177.7 & 652.4 & 21.2 \\
\hline
\end{tabular}




\begin{tabular}{|c|c|c|c|c|c|c|}
\hline$\frac{\text { Chronic condition }}{\text { Any of the following }}$ & $\begin{array}{c}-15.19 * * \\
(1.35)\end{array}$ & $\begin{array}{c}-27.15^{* *} \\
(1.76)\end{array}$ & $\begin{array}{c}18.25 * * \\
(4.22)\end{array}$ & 43.1 & 122.4 & 6.4 \\
\hline None of the following & $\begin{array}{l}-3.27 * * \\
(1.09)\end{array}$ & $\begin{array}{c}-8.19 * * \\
(1.77)\end{array}$ & $\begin{array}{l}-0.78 \\
(4.19)\end{array}$ & -6.8 & 42.7 & 1.7 \\
\hline Hypertension & $\begin{array}{c}-13.72 * * \\
(1.58)\end{array}$ & $\begin{array}{c}-27.27 * * \\
(1.88)\end{array}$ & $\begin{array}{c}25.02 * * \\
(7.43)\end{array}$ & 61.0 & 188.3 & 8.6 \\
\hline Hypercholesterolemia & $\begin{array}{c}-15.55^{* *} \\
(1.73)\end{array}$ & $\begin{array}{c}-28.69 * * \\
(1.14)\end{array}$ & $\begin{array}{c}3.14 \\
(7.61)\end{array}$ & 7.1 & 13.7 & 2.4 \\
\hline Asthma & $\begin{array}{c}-18.69 * * \\
(2.20)\end{array}$ & $\begin{array}{c}-46.91 * * \\
(2.04)\end{array}$ & $\begin{array}{c}13.90 \\
(28.18)\end{array}$ & 21.2 & 68.4 & 4.3 \\
\hline Diabetes & $\begin{array}{c}-20.13 * * \\
(1.58)\end{array}$ & $\begin{array}{c}-32.97 * * \\
(2.59)\end{array}$ & $\begin{array}{c}29.93 * * \\
(11.93)\end{array}$ & 56.4 & 153.4 & 8.5 \\
\hline Arthritis & $\begin{array}{c}-16.94 * * \\
(1.77)\end{array}$ & $\begin{array}{c}-27.94 * * \\
(2.45)\end{array}$ & $\begin{array}{c}30.66^{* *} \\
(5.54)\end{array}$ & 68.3 & 191.1 & 8.5 \\
\hline Affective disorders & $\begin{array}{l}-5.92 \\
(4.14)\end{array}$ & $\begin{array}{c}-58.20 * * \\
(5.37)\end{array}$ & $\begin{array}{c}44.60 * * \\
(17.60)\end{array}$ & 69.6 & 764.8 & 10.0 \\
\hline Gastritis & $\begin{array}{c}-18.58 * * \\
(3.36) \\
\end{array}$ & $\begin{array}{c}-33.68 * * \\
(2.23) \\
\end{array}$ & $\begin{array}{c}-5.59 \\
(14.48)\end{array}$ & -10.7 & -33.1 & -1.2 \\
\hline $\mathrm{N}$ & 104 & 100 & 104 & & & \\
\hline
\end{tabular}

$* *$ denotes significance at the $5 \%$ level.

* denotes significance at the $10 \%$ level.

Each cell in Columns 1-3 shows the coefficient from a separate difference-in-difference regression; standard errors are reported in parentheses. The dependent variable is indicated on the column heading; the subsample is indicated on the row label. Regressions control for plan and month fixed effects. They are estimated by GLS, allowing for plan-specific autocorrelation and plan-specific heteroskedasticity. All regressions exclude data from the 3 months before and after the relevant policy change, in order to eliminate the effects of any temporary shifts in the timing of care. There are 4 fewer observations used for the drug regressions, because we exclude February 2001, due to unusually large, one-time decreases drug purchases in the PPOs resulting from the February 2001 policy change.

Column 4 shows the increase in total hospital payments as a percentage of the decrease in office visit and drug payments. That is, it is equal to [-Column 3/ (Column $1+$ Column 2)]. Columns 5 and 6 show the same calculations for payments by Medicare and by supplemental insurance plans. Coefficients underlying the results in Columns 5 and 6 are available from the authors upon request. 
Figure 1: Effect of 2002 HMO Policy Change on Office Visits

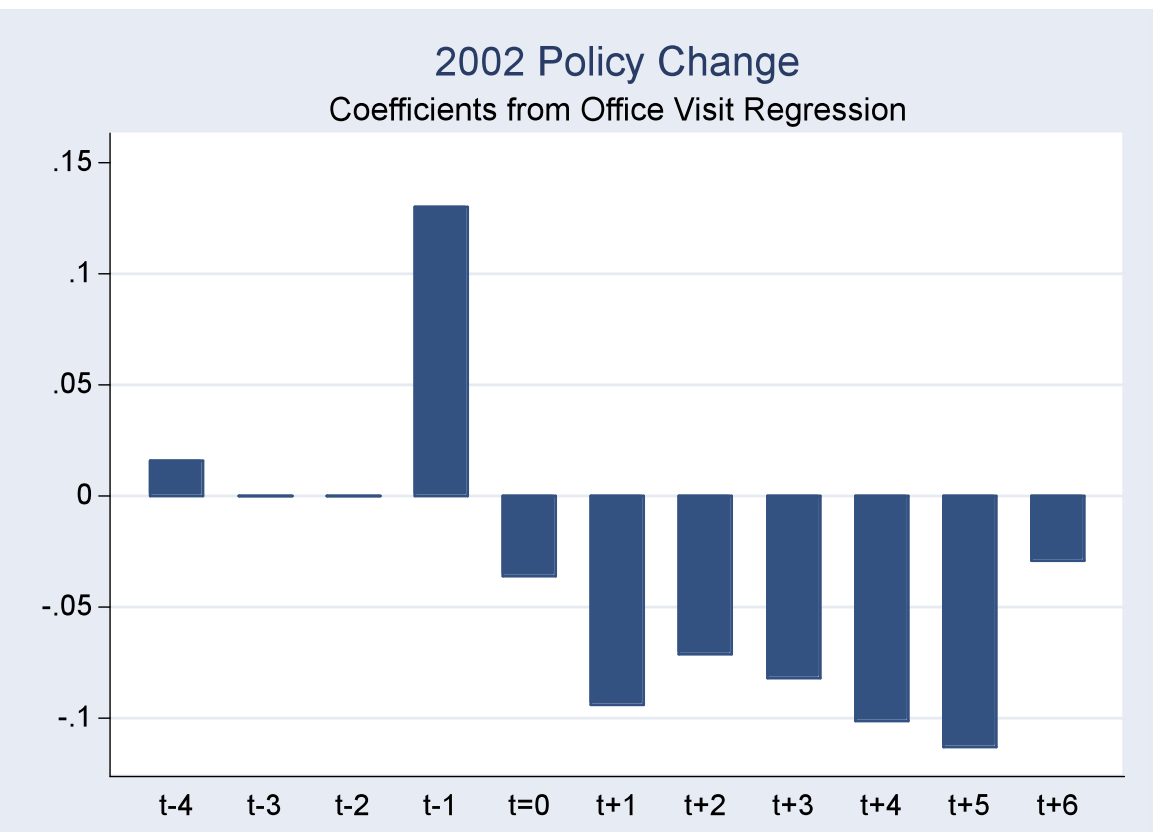

The bars show the point estimates from Column 3 of Table 2. 
Figure 2: Effect of Drug Copayment Policy Changes on Drug Utilization

Panel A: 2001 PPO Policy Change

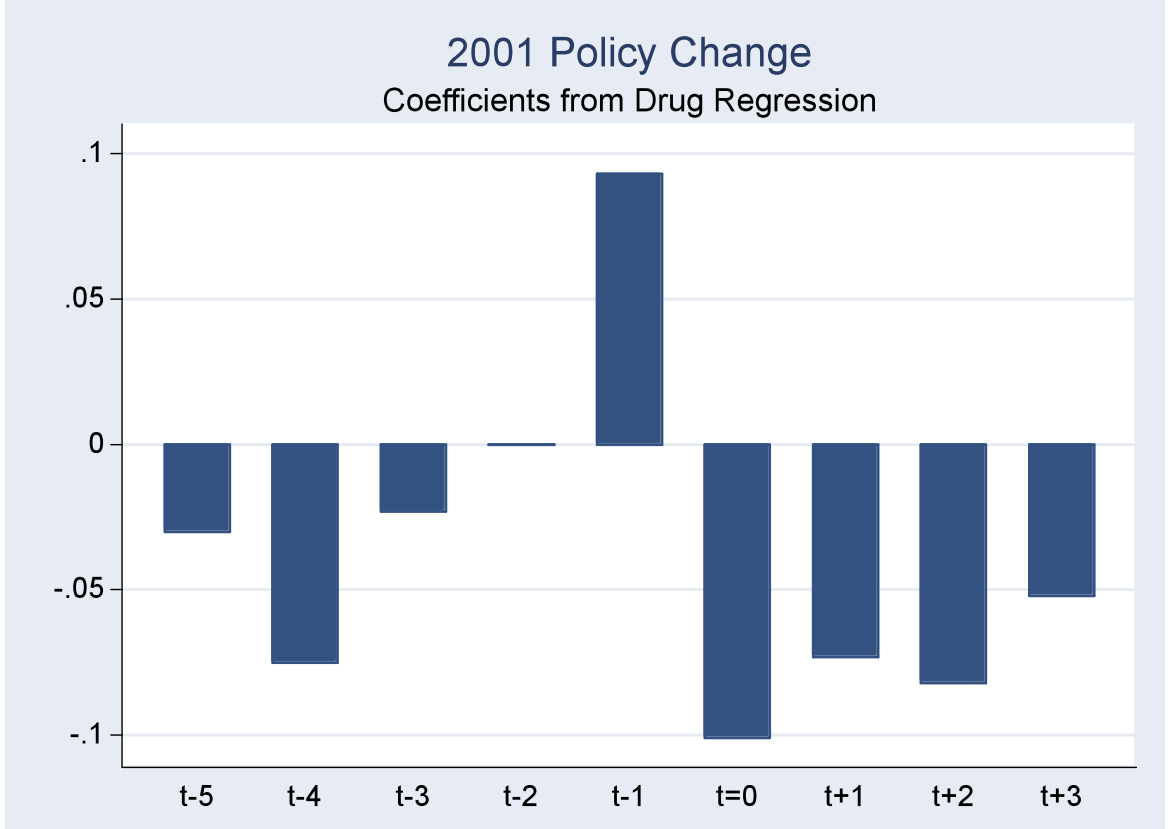

Panel B: 2002 HMO Policy Change

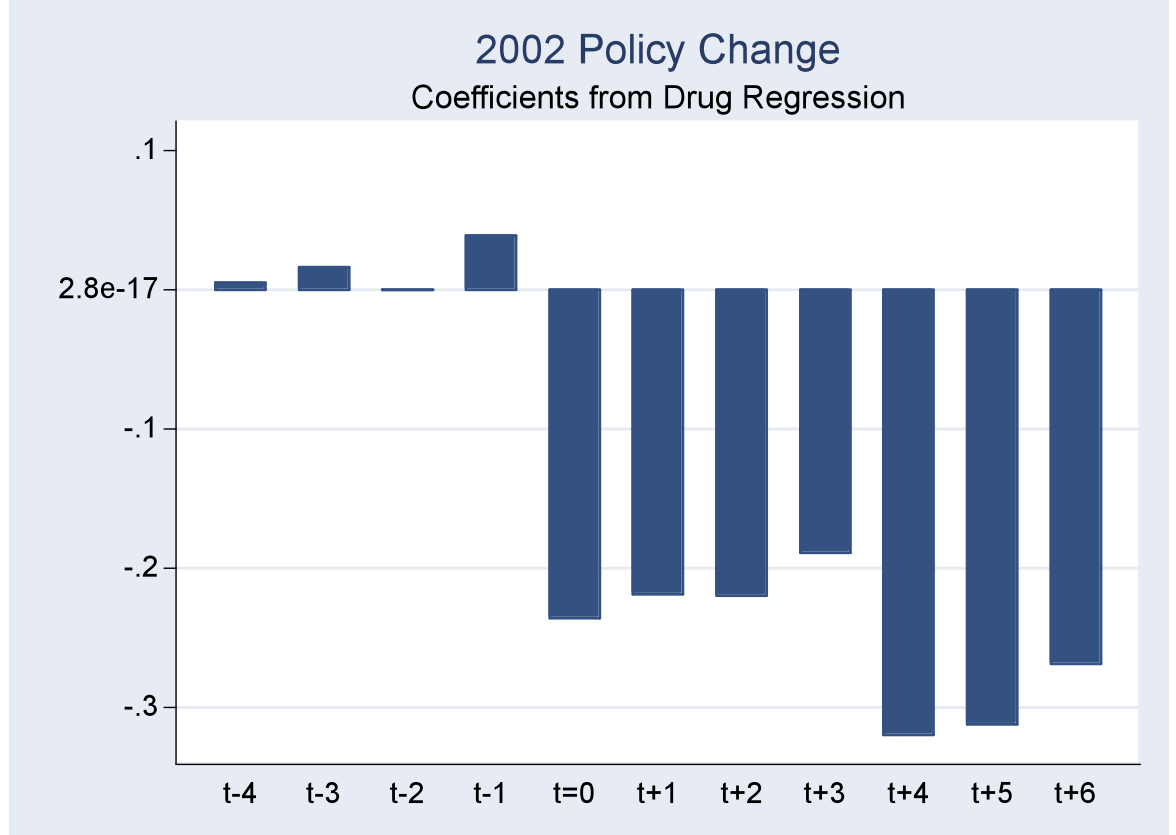

The bars show the point estimates from Columns 3 and 7 of Table 3 . 
Figure 3: Effect of Policy Changes on Hospitalizations

Panel A: 2001 PPO Policy Change

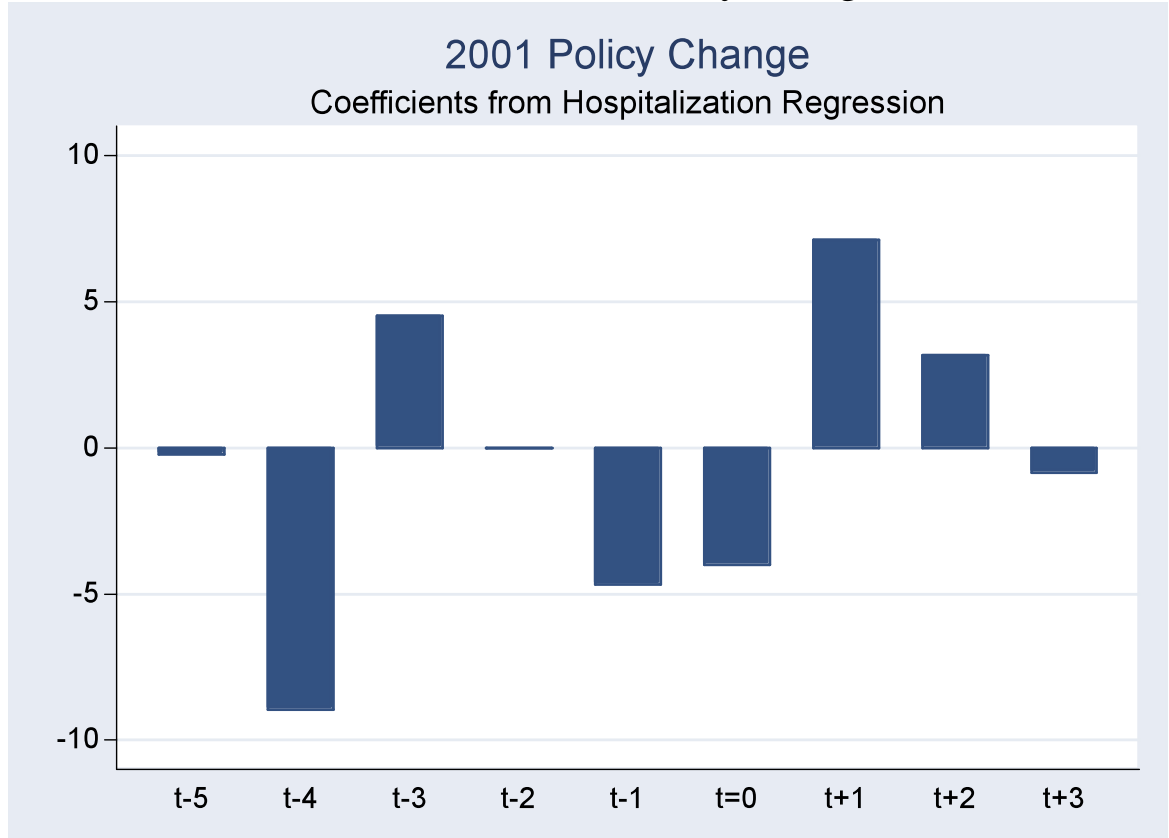

Panel B: 2002 HMO Policy Change

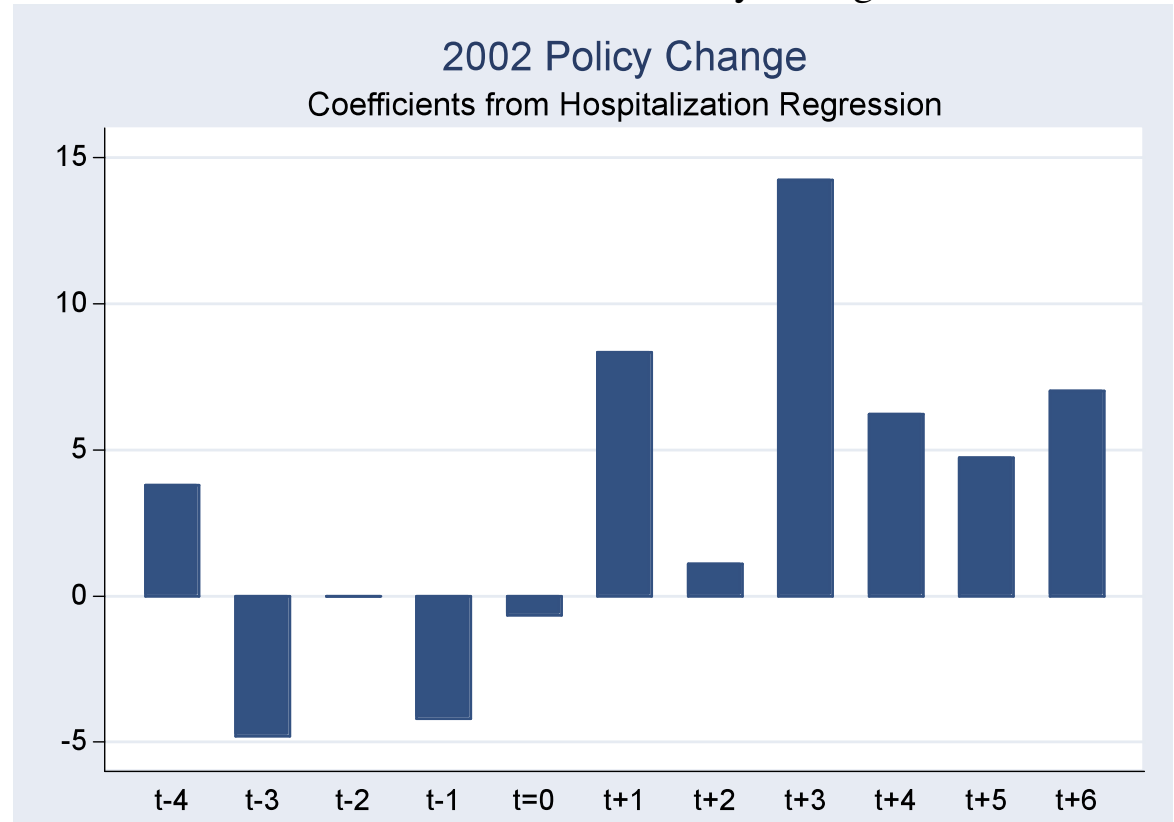

The bars show the point estimates from Column 2 and 5 of Table 4 . Note that all values in this figure and in Table 4 are multiplied by 10,000. 